\title{
التحكيم في المنازعات الرياضية وفق قواعد محكمة التحكيم الرياضية الدولية
}

\author{
عايد أحمد عايد الخرابشة \\ طالب دكتوراة- جامعة العلوم الإسلامية العالمية- الأردن \\ sahelaliatoom@gmail.com
}


www.refaad.com
المجلة الدولية للدراسات القانونية والفقهية المقارنة

International Journal of Legal and Comparative Jurisprudence Studies (LCJS)

Journal Homepage: https://www.refaad.com/views/LCJS/Home.aspx

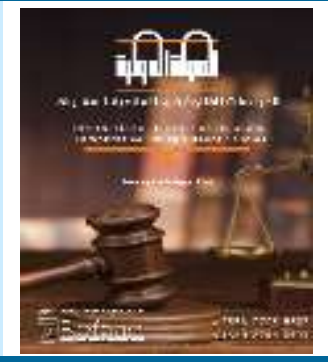

ISSN: 2708-6607(Online) 2708-6593(Print)

\title{
التحكيم في المنازعات الرياضية وفق قواعد محكمة التحكيم الرياضية الدولية
}

\author{
عايد أحمد عايد الخر ابشـة \\ طالب دكتوراة- جامعة العلوم الإسلامية العالمية- الأردن \\ sahelaliatoom@gmail.com
}

DOI: https://doi.org/10.31559/LCJS2021.2.1.2 2020/12/31 مراجعة البحث: 2021/2/17 قبول البحث: 2021/3 مرام

هدفت هذه الدراسة إلى التعرف على التحكيم في المنازعات الرياضية وفق قواعد محكمة التحكيم الرياضية الدولية، من خلال التعرف على طبيعة اختصاصات هذه المحكمة وطبيعة النزاعات التي تنظر فيها، وكذلك القواعد القانونية المطبقة، والوقوف على هلى إجراءات التحكيم والتسوية في النزاعات الرياضية في محكمة التحكيم الرياضية الدولية، وتظهر إشكالية الدراسة من خصوصية محكمة التحكيم الرياضية في أنها تنظر في جميع النزاعات التي تنشأ في المجال الرياضي وهذاء يخالف قواتئ قواعد ومبادئ التحكيم الدولي، وكذلك اختلاف القواعد المطبقة في حسم تلك النزاعات في المجال الرياضي، ولتحقيق أهداف الدراسة تم الاعتماد على المنهج الوصفي التحليلي، وذلك من خلال إستعراض المفاهيم المختلفة والمتعلقة بموضيوع الدراسة، والتعرف على شكل وتكوين وإجراءات عمل وسير محكمة إسل التحكيم الرياضي الدولي.

وقد توصلت الدراسة إلى مجموعة من النتائج من أهمها: أن النزاعات الرياضية تنشأ في مجال الأنشطة الرياضية أياً كان نوع النشاط الرياضي، وهي نزاع أو خلاف قانوني بصدد علاقة قانونية ذات طابع رياضي من أي نوع كانت، وأن محكمة التحكيم الرياضية مؤسسة

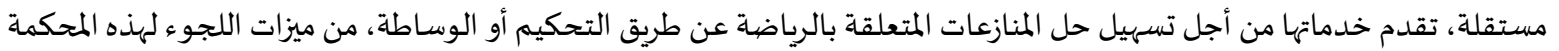

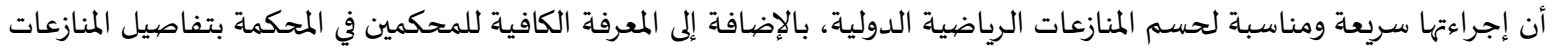

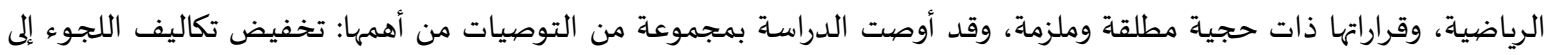
محكمة التحكيم الرياضي الدولية، وإنشاء فروع لها في مختلف مناطق العالم بهدف تسهيل الوصول إليها، وحتى لا يحدث ترديه تردد من المتنازعين للجوء إليها، وكذلك السعي نحو اعتماد اللغة العربية كلغة أساسية معتمدة ثالثة جنباً إلى جنب مع اللغة الفرنسية ولهية والإنجليزية في محكمة التحكيم الرياضي الدولية. الكلمات المفتاحية: التحكيم الرياضي الدولي؛ منازعات رياضية؛ محكمة التحكيم الرياضية الدولية.

مارس الإنسان منذ قديم الزمان رياضات مختلفة، كما عرفت الحضارات المختلفة الرياضة بأنواعها، بل إن كثيراً من النّشاط الإنساني يُمارس

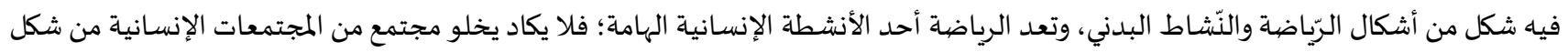

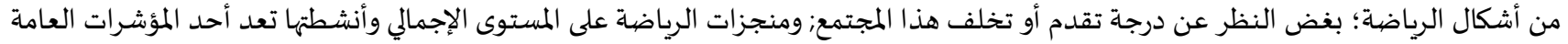


التي يحكم من خلالها على مستوى التقدم الإجتماعي والثقافي لمجتمع ما؛ فالرياضة ظاهرة اجتماعية ثقافية متداخلة بشكل عضوي في نظام الكيانات

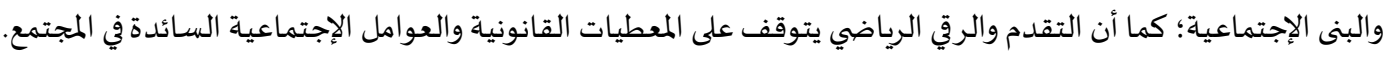

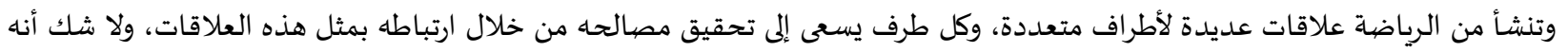

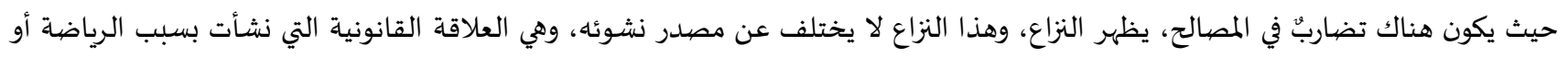

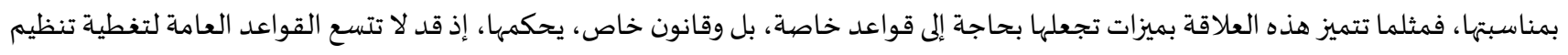

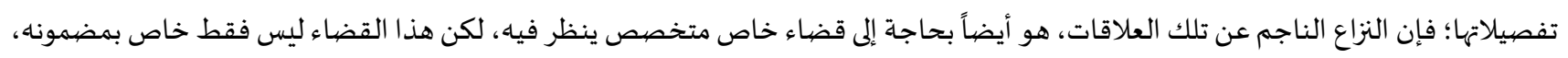

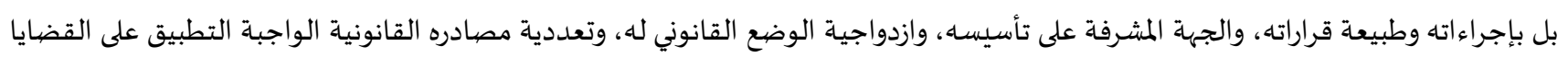
المعروضة عليهاء (1).

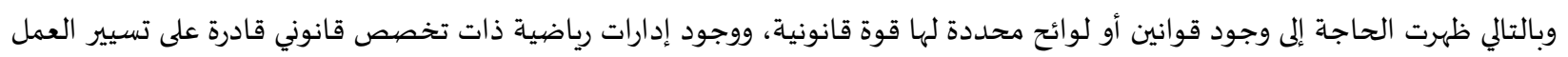

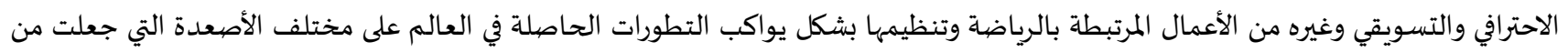

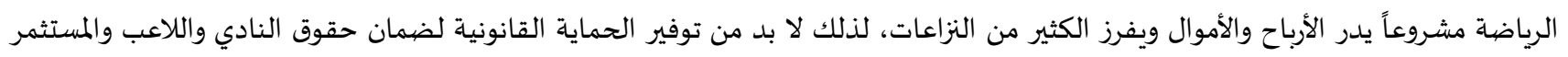

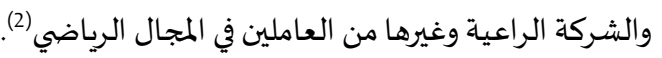

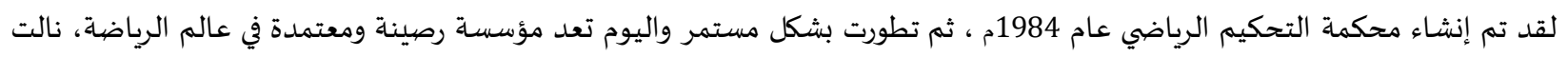

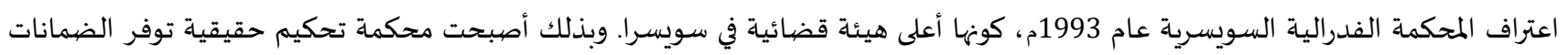

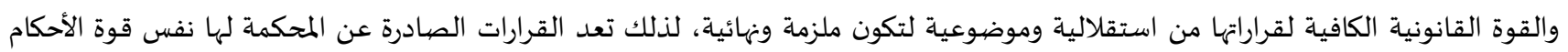
القضائية الصادرة عن المحاكم العادية (3).

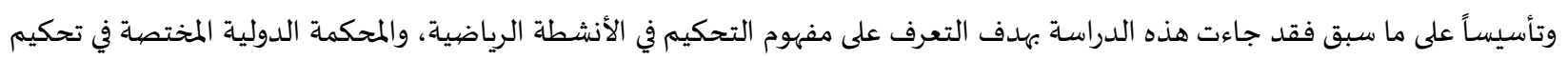
النزاعات الرياضية.

مشكلة الدراسة وأسئلتها:

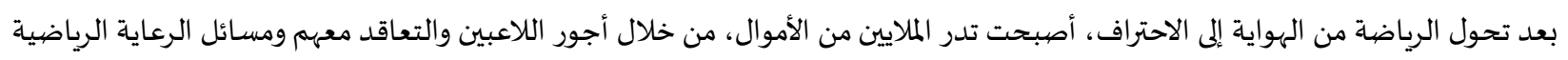

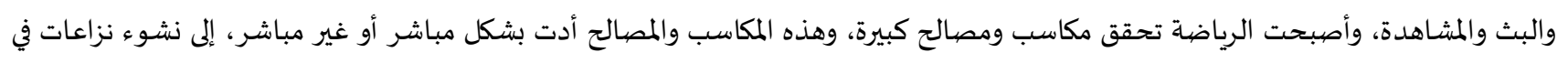

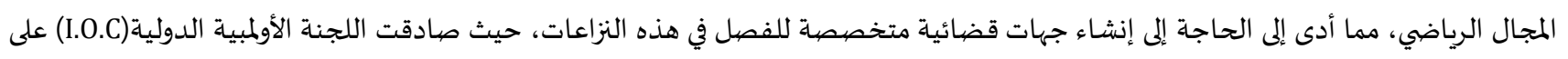

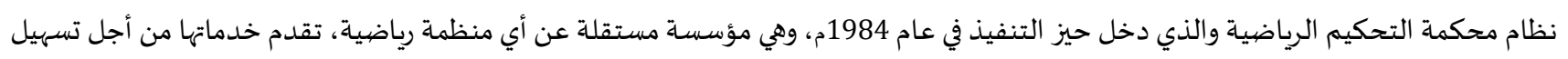

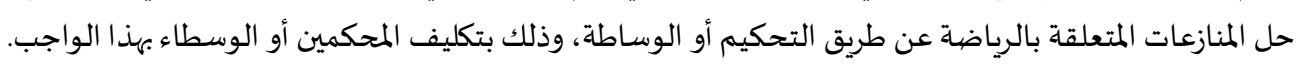

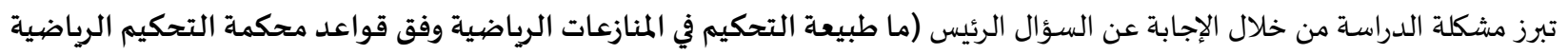
الدولية؟)، ويتفرع من هذا السؤال الأسئلة الفرعية الآتية:

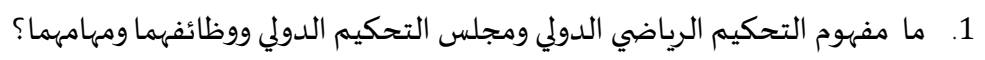

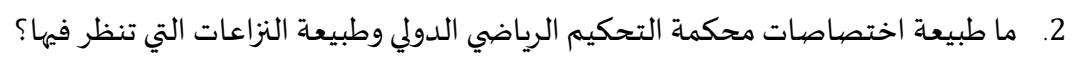
3.

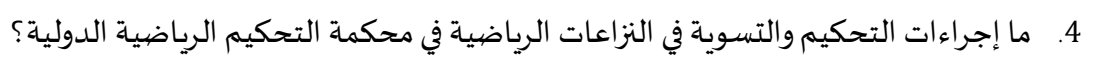

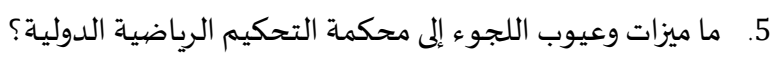

تسعى هذه الدراسة إلى تحقيق الأهد اف التالية:

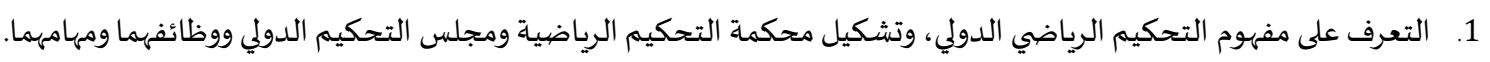
2.

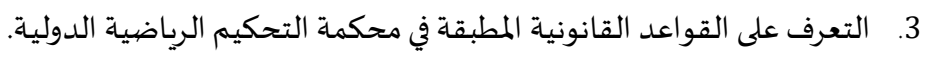
4. الوقوف على إجراءات التحكيم والتسوية في النزاعات الرياضية في محكمة التحكيم الرياضية التربية الدية الدولية.

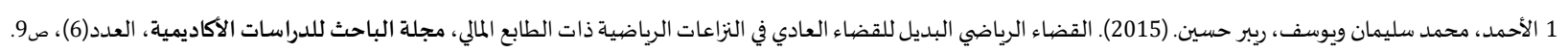

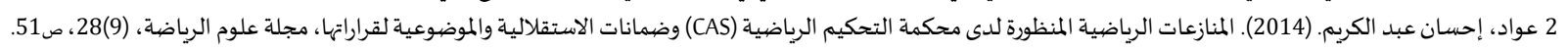

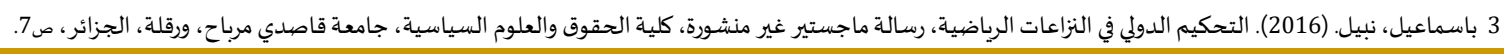


تكمن أهمية الدراسة في أن الرياضية أصبحت من أهم الظواهر الإجتماعية التي يتم الاهتمام بها على المستوى الدولي، فلم يعد ينظر إلهيها على أنها

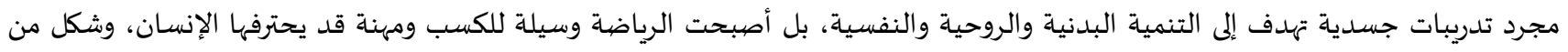

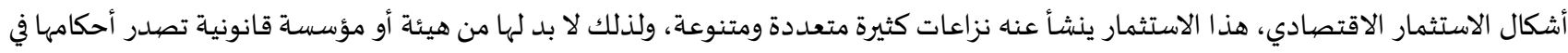

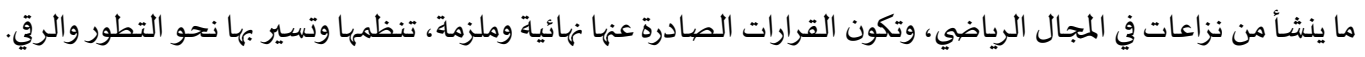

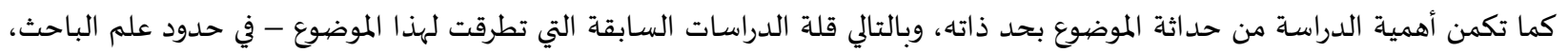

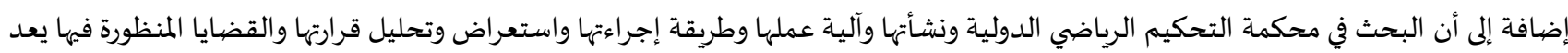
من الأهمية بمكان لكل الجهات والمؤسسات والأفراد ذوي العلاقة البحات بالمجال والأنشطة الرياضية.

منهجية الدراسة:

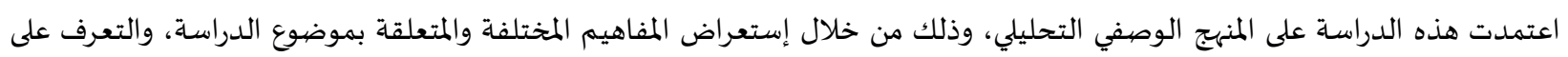

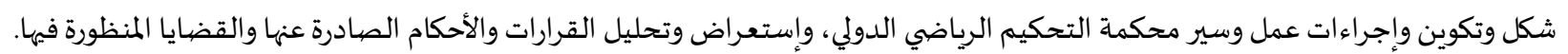

$$
\begin{aligned}
& \text { خطة الدراسـة: - (ماس } \\
& \text { شملت هذه الدراسة بالإضافة إلى المقدمة والخاتمةة، ثلاثة فصول، كالآتي: }
\end{aligned}
$$

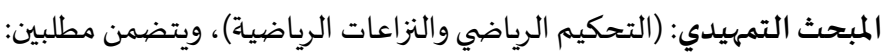

$$
\begin{aligned}
& \text { - المطلب الأول: ماهية التحكيم الرياضي الدولي. ويتكون من فرعين: } \\
& \text { الفرع الأول: مفهوم التحكيم الرياضي الدولي. } \\
& \text { الفرع الثاني: وظائف محكمة التحكيم الرياضي ومهامها. } \\
& \text { - المطلب الثاني: مفهوم النزاعات الرياضية وطبيعتها، ويتكون من فرعين: }
\end{aligned}
$$

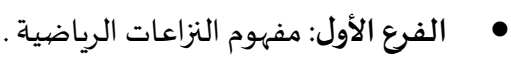

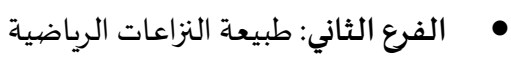

$$
\begin{aligned}
& \text { المبحث الأول: (محكمة التحكيم الرياضية الدولية)، ويتضمن مطلبين: } \\
& \text { - - - ملمطلب الأول: طبيعة اختصاصات محكمة التحكيم الرياضية الدولية، ويتكون من فرعين: } \\
& \text { الفرع الأول: النزاعات ذات الطبيعة التجارية } \\
& \text { الفرع الثاني: النزاعات ذات الطبيعة التأديبية. } \\
& \text { - المطلب الثاني: القواعد القانونية المطبقة في محكمة التحكيم الرياضية الدولية، ويتكون من فرعين: }
\end{aligned}
$$

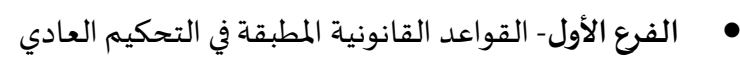

$$
\begin{aligned}
& \text { الفرع الثاني- القواعد القانونية المطبقة في التحكيم الاستئنافي } \\
& \text { المبحث الثاني: (قرارات محكمة التحكيم الرياضية الدولية)، ويتضمن مطلبين: } \\
& \text { - المطلب الأول: إجراءات التحكيم (التسوية - الاستئناف) أمام محكمة التحكيم الرياضية الدولية، ويتكون من فرعين: }
\end{aligned}
$$

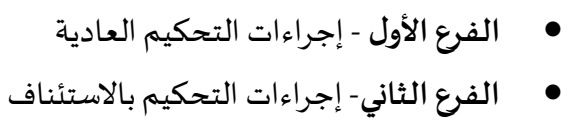

$$
\begin{aligned}
& \text { - المطلب الثاني: حجية قرارات محكمة التحكيم الرياضية الدولية. } \\
& \text { الفرع الأول- حجية القرارات } \\
& \text { الفرع الثاني- مزايا وعيوب اللجوء إلى محكمة التحكيم الرياضية الدولية }
\end{aligned}
$$




\section{المبحث التمهيدي: التحكيم الرياضي والنزاعات الرياضية}

نتيجة لتطور وانتشار الرياضة بشكل واسع في معظم دول العالم، بالإضافة إلى تعقد طبيعة النشاط الرياضي والرياضيين والهيئات الرياضية

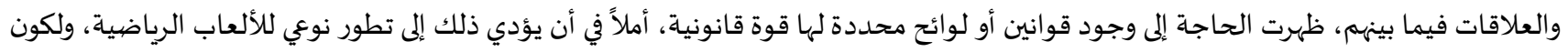

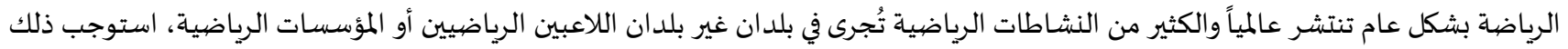

$$
\text { وجود التحكيم الرياضي الدولي. }
$$

المطلب الأول: ماهية التحكيم الرياضي الدولي

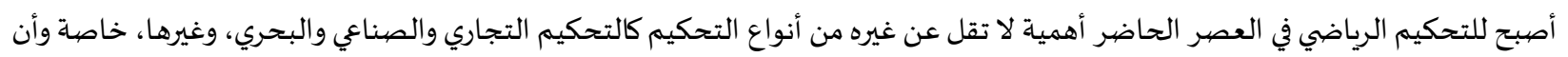

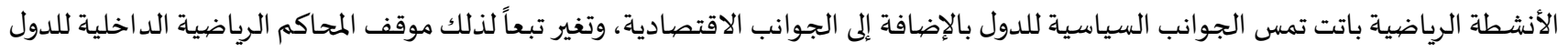

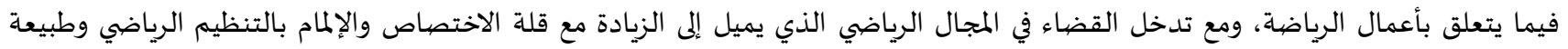

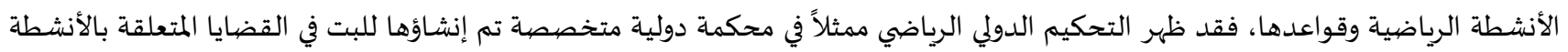
الرياضية العالمية.

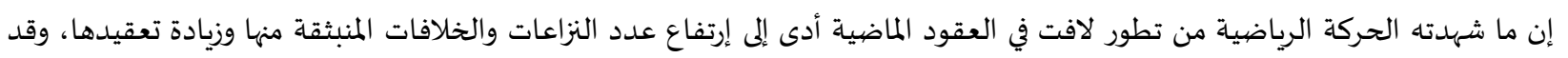

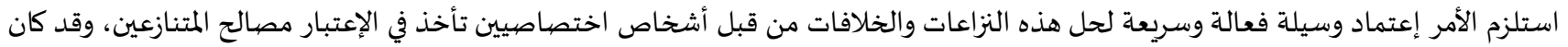

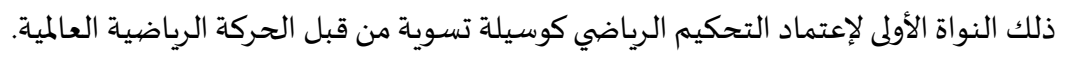

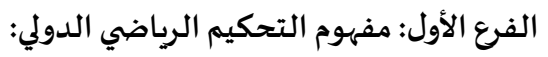

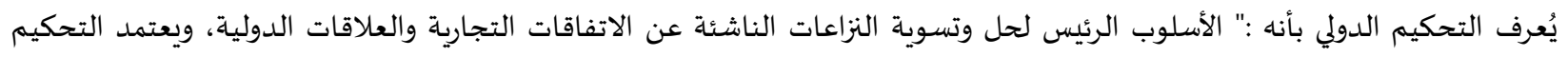

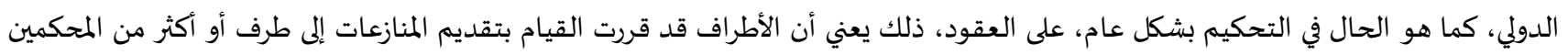

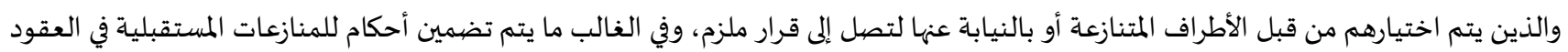

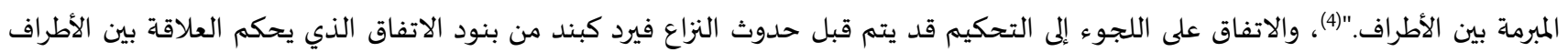

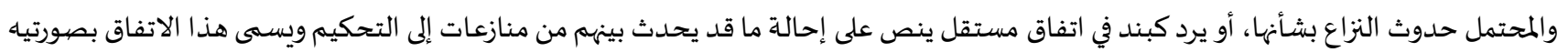

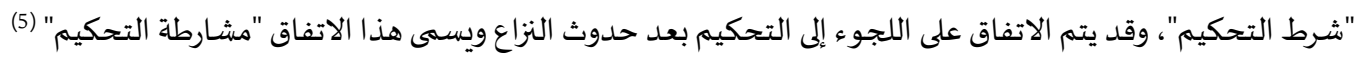

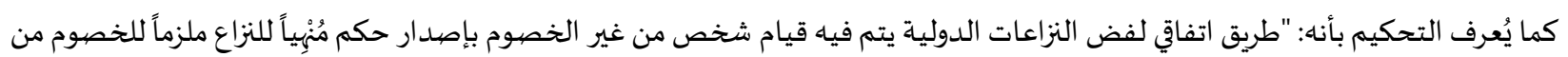

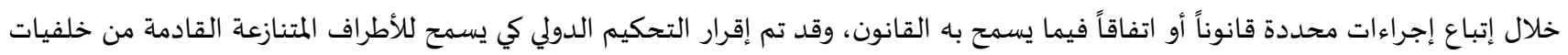

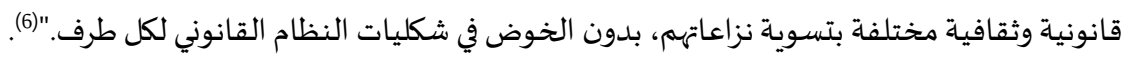

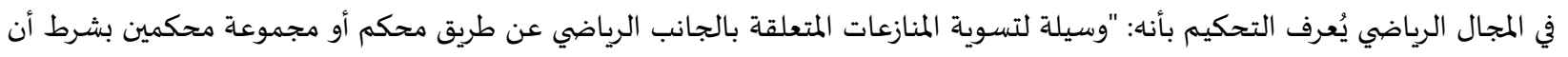

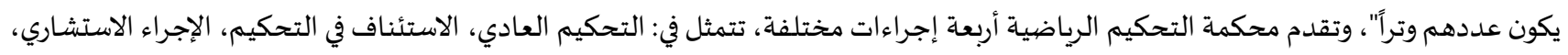
والوساطة).

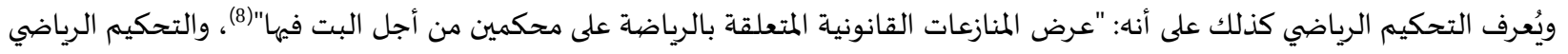

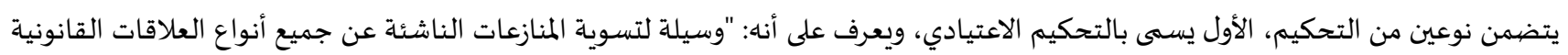

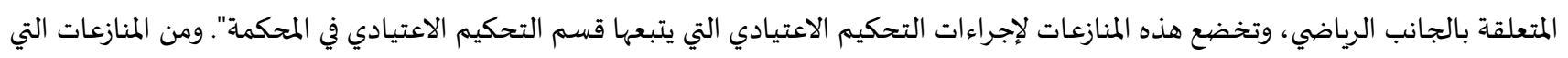

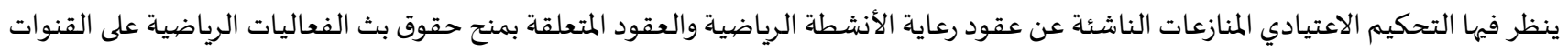

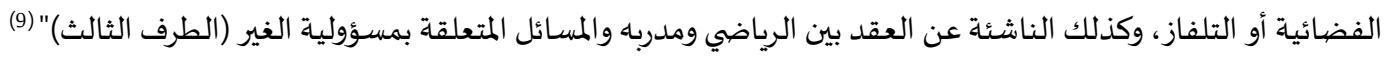

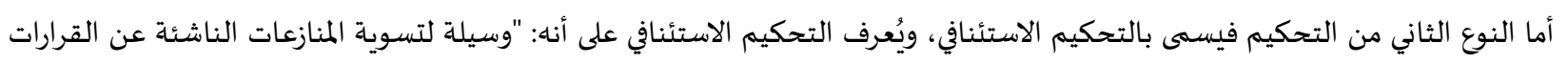

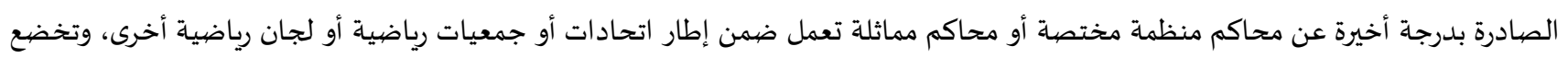

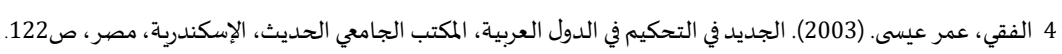

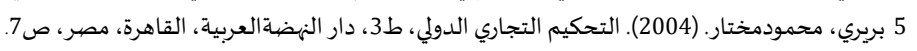

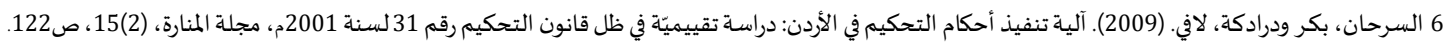

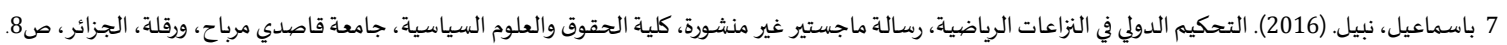

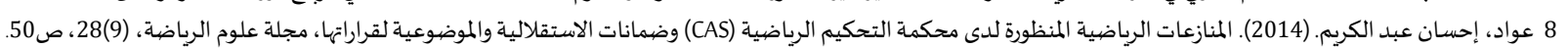

9 المرجع السابق، صع8. 
هذه المنازعات لإجراءات التحكيم الاستئنافي التي يتبعها قسم التحكيم الاستئنافي في المحكمة"(10). ومن أمثلة هذه المنازعات نذكر المنازعات الناشئة عن

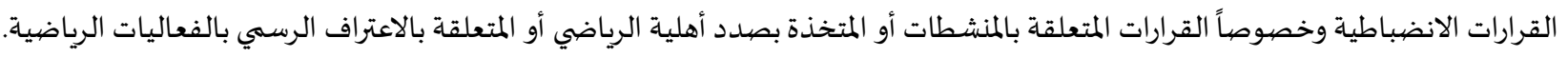

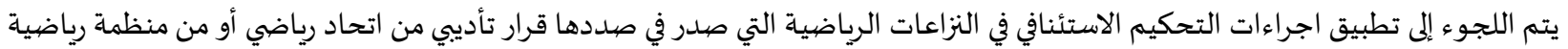

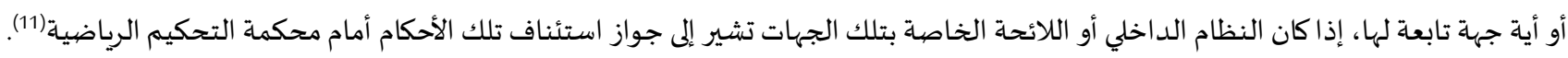

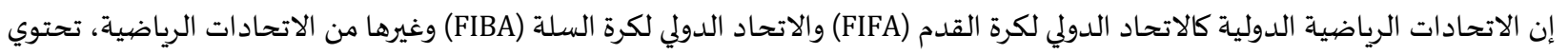

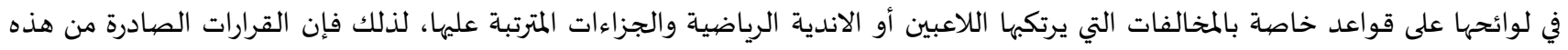

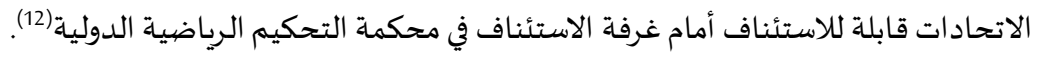
الفرع الثاني: وظائف محكمة التحكيم الرياضي ومهامها: عندما تتجهه إرادة أطراف النزاع في حقل الرياضية الدولية إلى اللجوء إلى التحكيم، فإنهم يعبرون عن نيتهم إخراج النزاع من سلطة القضياء الوطني

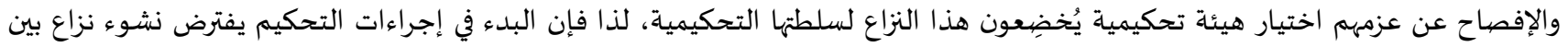

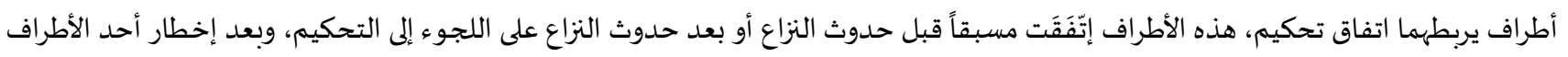

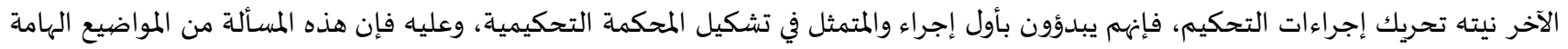

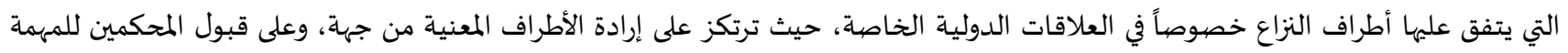
المسندة إلههم من جهة أخرى(13)

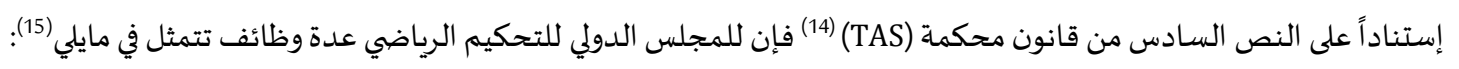
1. إنشاء وتعديل قانون المحكمة.

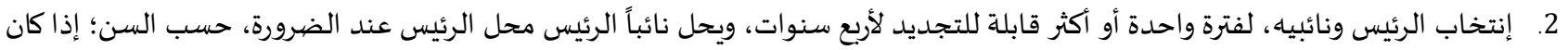

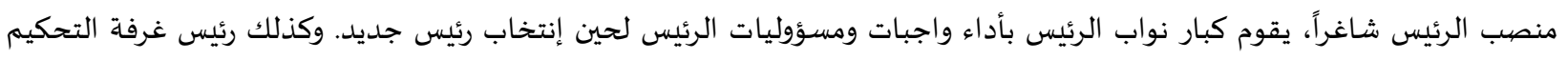
العادية ورئيس غرفة تحكيم الاستئناف لمحكمة التحكيم (TAS)، وإنتخاب نائبين إثنين لرؤساء الغرف لتمكين إستبدالهما في حالة غيابهم، ويتم

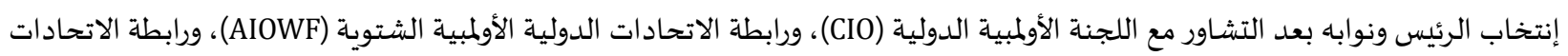
الدولية الأولمبية الصيفية (ASOIF)، ورابطة اللجان الونئنية الوطنية الأولمبية (ACNO).

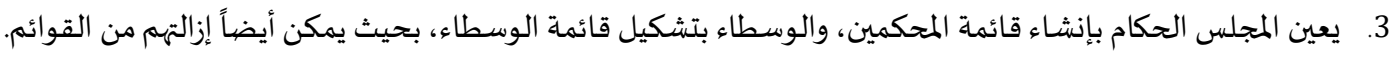

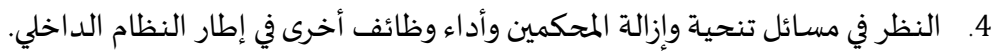
5. تعيين الأمين العام للمحكمة (TAS)، كما يستطيع إنهاء مهامهاء باقتراح من قبل رئيسـاء.

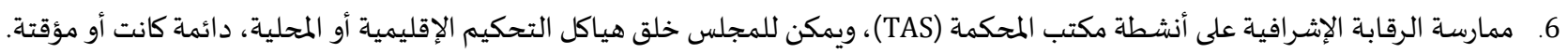

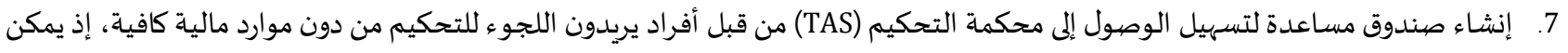

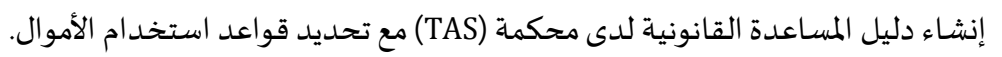

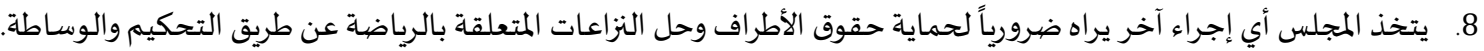
9 . الاجتماع وكيفياته وكذلك كيفيات التصويت وغيرها... فإن أغلبها يخضع للقواعد العامة في التحكيم.

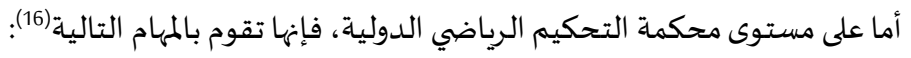
1. البت في النزاعات المقدمة لههم من خلال التحكيم العادي.

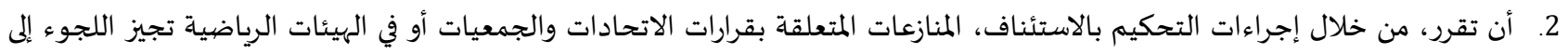

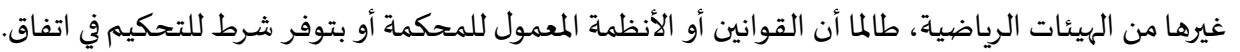
3. البت في النزاعات المقدمة إلهها عن طريق الوساطية.

10 المرجع السابق، ص58. 11 الأحمد، محمد سليمان ويوسف، ريبر حسين. (2015). القضاء الرياضي البديل للقضاء العادي في النزاعات الرياضية ذات الطابع المالي، مرجع سابق، ص18. 12 المرجع السابق، ص18. 13 الدليل، محمد أبو الفتوح. (2013). قانونية تأسيس المحكمة الرياضية بجمههورية مصر العربية، أطروحة دكتوراة غير منشورة، كلية التربية الرياضية للبنين، جامعة بنها، ص84.

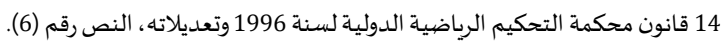

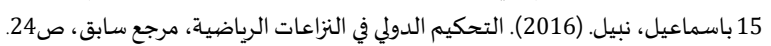

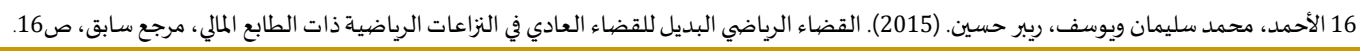


المطلب الثاني: مفهوم النزاعات الرياضية وطبيعتها

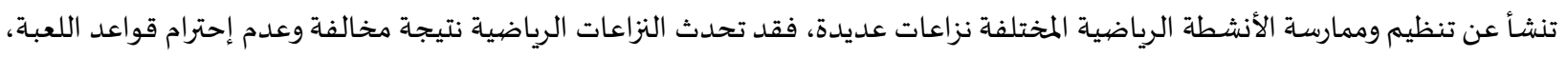
وقد تتعلق النزاعات الرياضية بإدارة وإشراف وتنظيم الأنشطة الرياضية، وتنظيم العلاقات بين القائمين عليها وبين ممارسيها، كما هو الحال بالنسبة

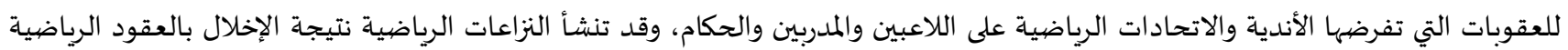

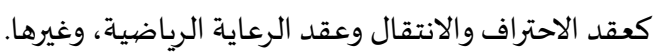

الفرع الأول: مفهوم النزاعات الرياضية:

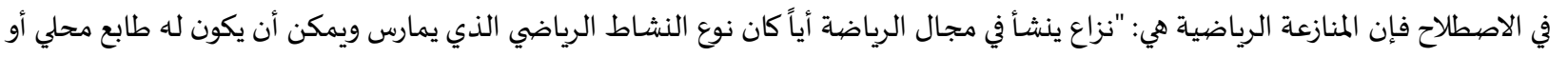
دولي وقد أدى دخول عنصر الاحتراف في العصر الحالي إلى تعقد الأمور وضرورة تطبيق قواعد القانون على العلاقات الناشئة على هذا العنصئر الجديد"(17).

وعرفت المنازعات الرياضية على أنها: "ما يحدث نتيجة عنف عند ممارسة اللعبة أو عدم احترام لقواعد وقوانين الممارسة الرياضية سواء الإدارية

أو الفنية أو ما يتعلق بإدارة الرياضية والإشراف عليها وتنظيم العلاقات بين القائمين عليها وبين ممارسيهات" (18).

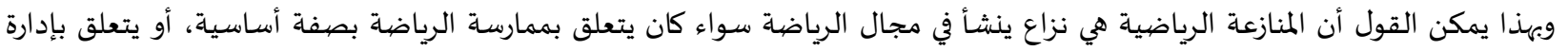
الرياضة والإشراف عليها وتنظيم العلاقات بين القائمين عليها وبين ممارسيها.

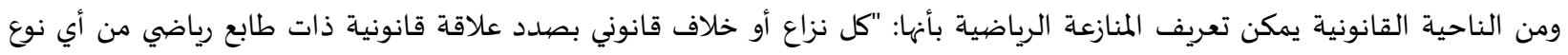

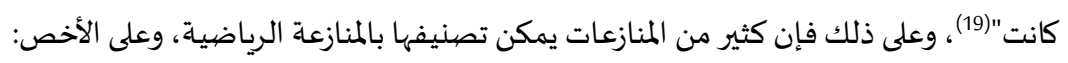
خلافات الاتفاق على رعاية اللاعبين.

مسألة تعاطي المنشطات أثناء ممارسـة الرياضية. الخلاف حول تنفيذ عقود إلتحاق أو احتراف اللاعبين بالأندية. الخلاف حول حصرية حقوق البث التلفزيوني أو الفضائي بين الأندية أو الكيانات الرياضية. الخلاف حول حقوق اللاعبين المالية قبل الأندية. الخلاف حول مسائل انتقال اللاعبين من وإلى الأندية. الخلاف حول تنفيذ عقود الوكلاء الرياضيين وعقود الوكالة بصفة عامة في المجال الرياضي. الشكاوى أو الطلبات التي تقدم للتعويض والمقامة بين اللاعبين ضهد نواديهم بشأن التعسف في إستعمال الجزاء قبلهم .

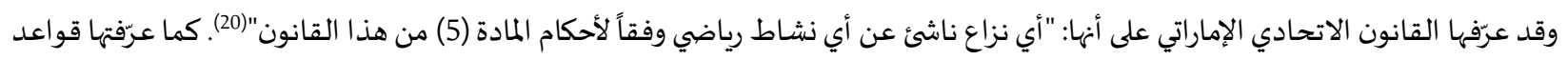

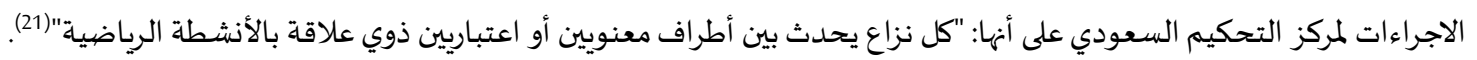

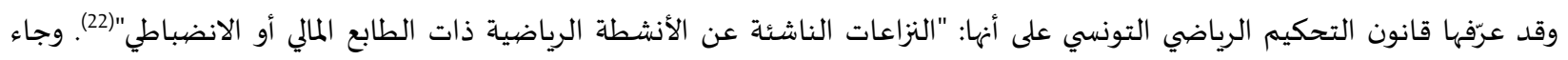

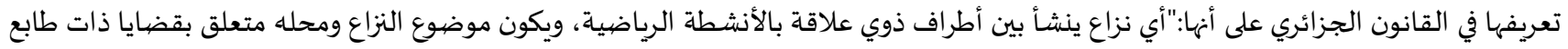
مالي أو إداري أو تأديبي"(23). الفرع الثاني: طبيعة النزاعات الرياضية: إدئي تم إنشاء محكمة التحكيم الرياضية كمؤسسة مستقلة عن أي منظمة رياضياة، تقدم خدماضئهاتهاتها من أجل تسوية المنازعات المتعلقة بالرياضة من

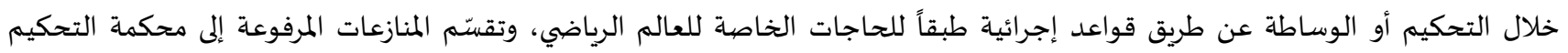
الرياضية، من حيث طبيعتها، على نوعين: النزاعات ذات الطبيعة المالية والنزاعات ذات الطبية الطبيعة الانضبياطية (الوقائع الرياضياة)(24).

17 شهبو، نبيل. (2003). الضوابط القانونية للمنافسة الرياضية، رسالة دكتوراة غير منشورة، كلية التربية الرياضية للبنين، جامعة حلوان، مصر، صألم6.

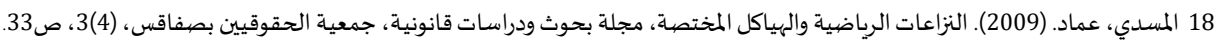

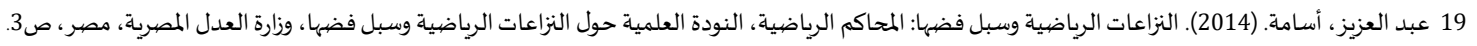

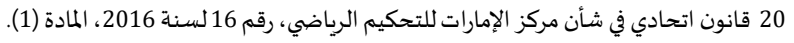

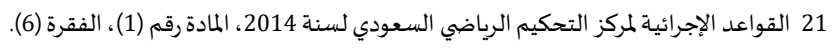

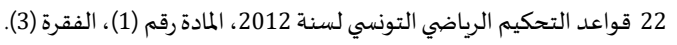

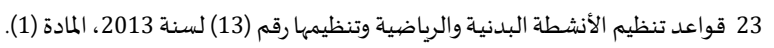

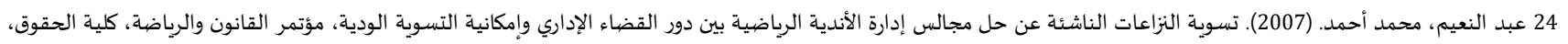


ترتبط عملية تنظيم المسابقات الرياضية باتفاقات كثيرة وعقود مالية متنوعة، ويمكن تصنيف العقود التي تبرم بمناسبة تنظيم المسابقات

الرياضياة إلى ثلاثة أصناف(25):

عقود مُهيئة للمسابقة: وهي التي تنعقد لأجل تهيئة إجراء المسابقة الرياضية، كعقود نقل المتسابقين إلى محل إقامة المسابقة، وعقود إيواء المتسـابقين القادمين من أماكن بعيدة وإطعامهم، وعقود تنظيف مكان الإقامة، بالإضافة إلى عقود تهيئة معدات ومستلزمات إجراء المسابقة

عقود مسببة لأداء المسابقة: وهي العقود التي لولاها لما نُظّمت المسابقة أصلاً، كعقود احتراف اللاعبين وإنتقالهم. عقود مباشرة وداعمة لأداء المسـابقة الرياضية: كالعقود المبرمة بين المساهمين في تنظيم المسابقة، العقود المبرمة مع المتفرجين، والعقود

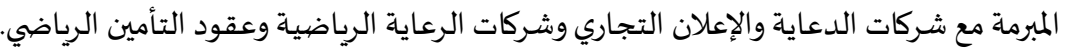

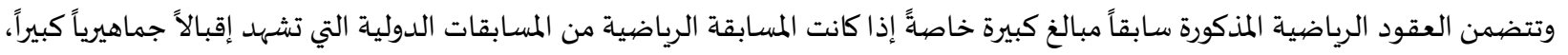

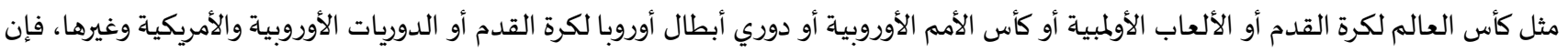

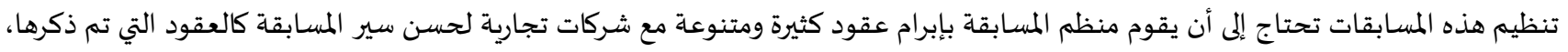

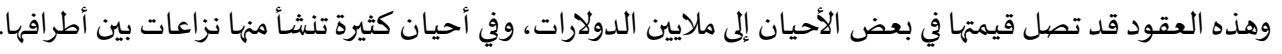

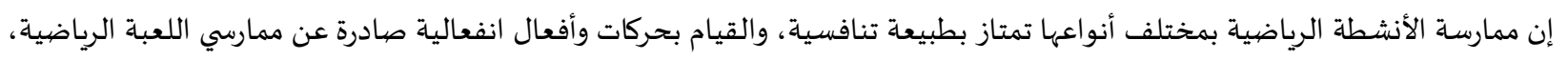

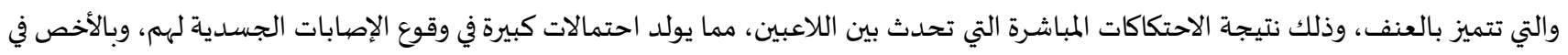

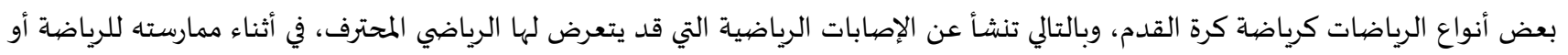

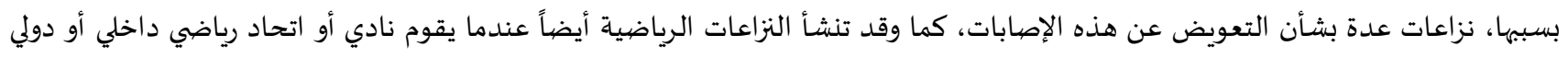

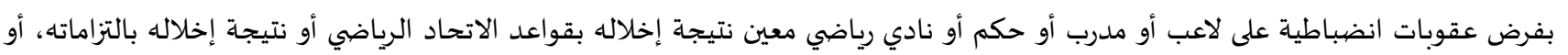

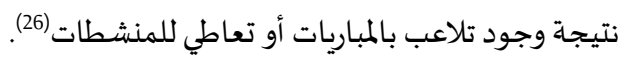

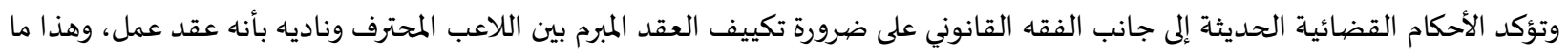

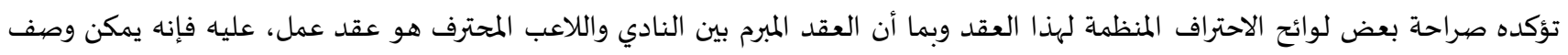

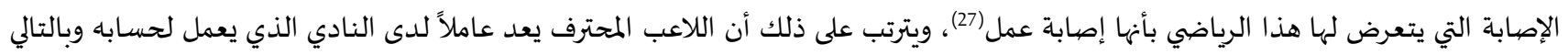

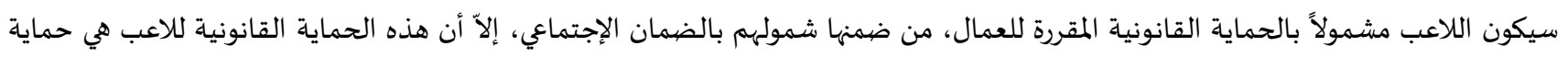

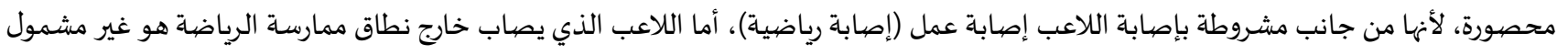

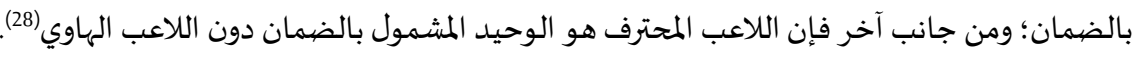

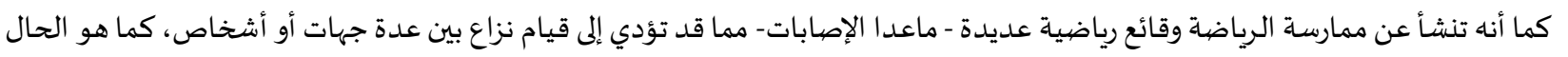

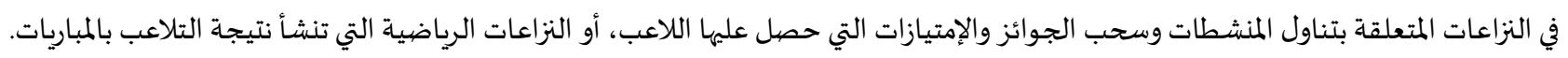

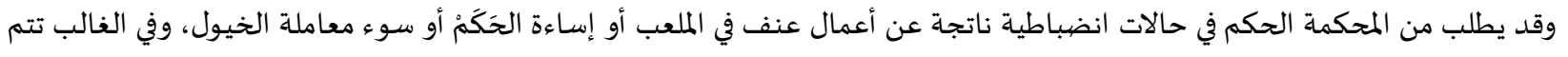

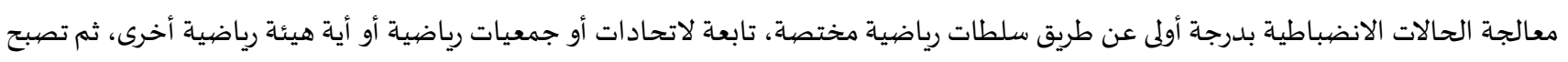

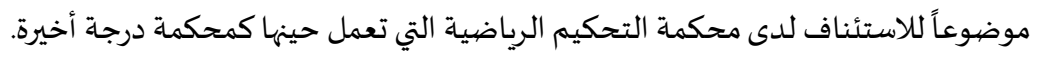

\section{المبحث الأول: محكمة التحكيم الرياضية الدولية}

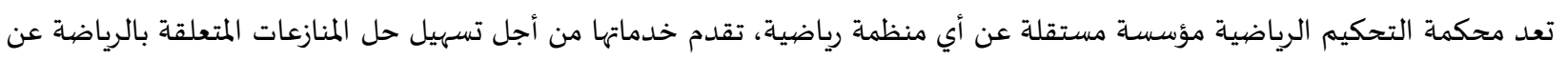

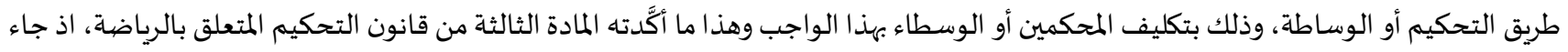

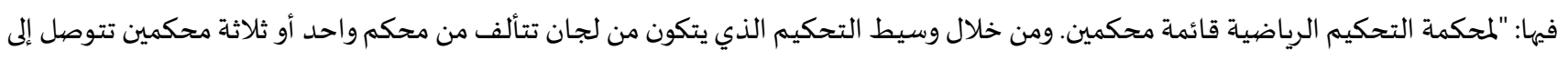

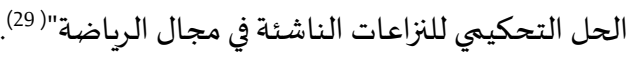

25 الأحمد، محمد سليمان ويوسف، ريبر حسين. (2015). القضاء الرياضي البديل للقضاء العادي في النزاعات الرياضية ذات الطات الطابع المالي، مرجع سابق، ص17.

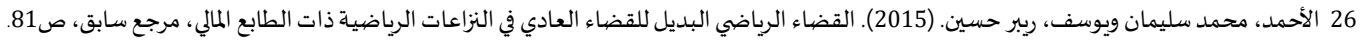

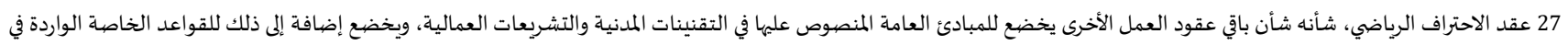

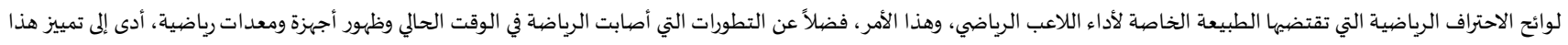
العقد بخصوصيات ينفرد بها عن عقود العمل الأخرى.

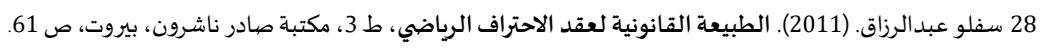
29 قواعد إجراءات التحكيم الرياضي CAS، المادة (3) . 
المطلب الأول: طبيعة اختصاصات محكمة التحكيم الرياضية الدولية

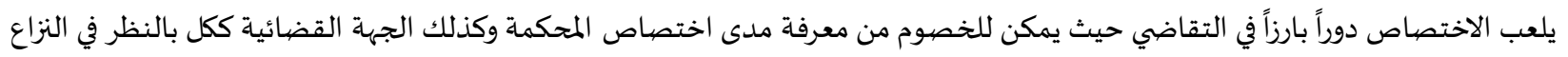

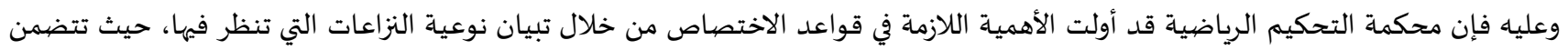

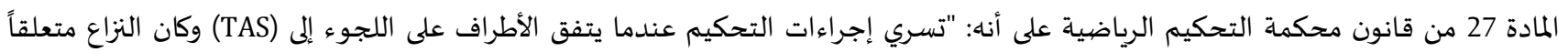

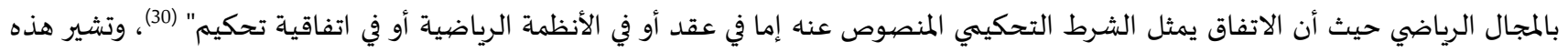

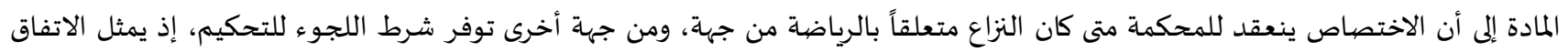

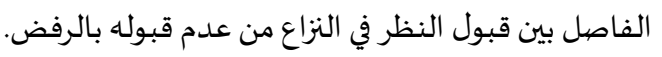

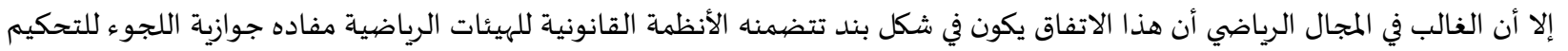

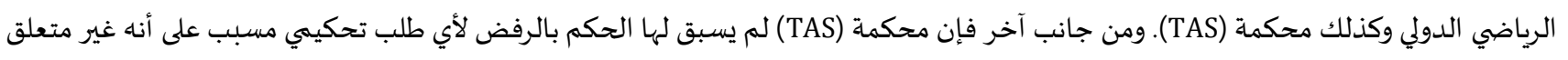
بالرياضة.

الفرع الأول: النزاعات ذات الطبيعة التجارية:

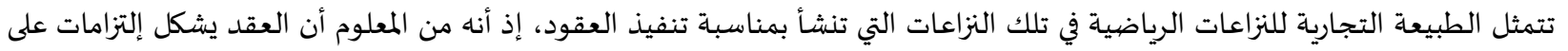

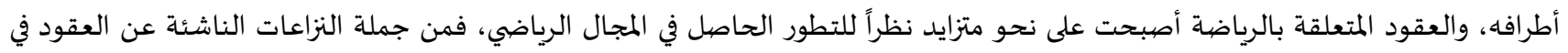

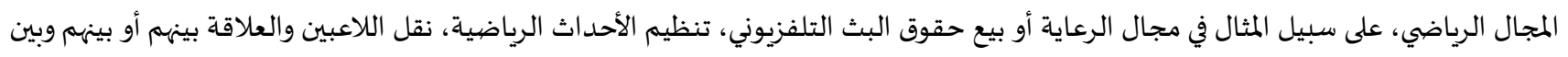

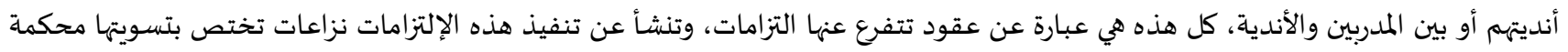

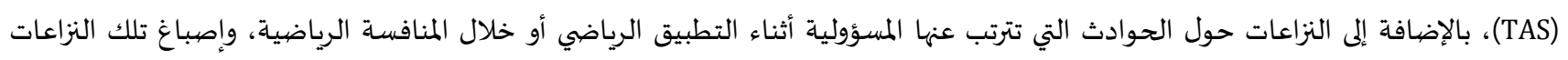

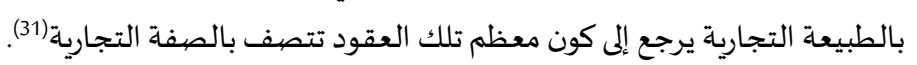

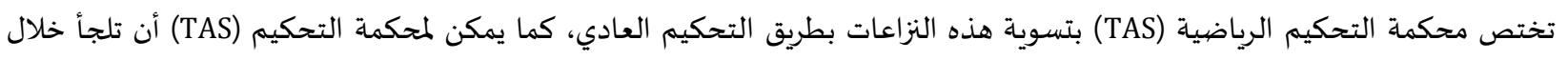

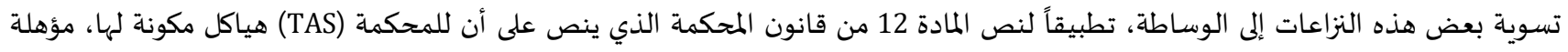

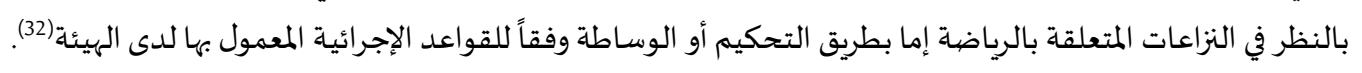
الفرع الثاني: النزاعات ذات الطبيعة التأديبية:

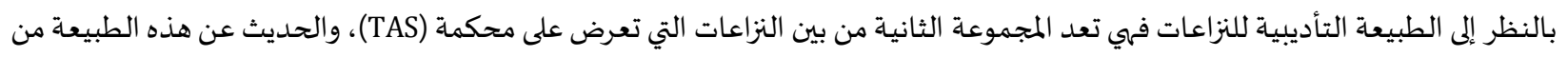

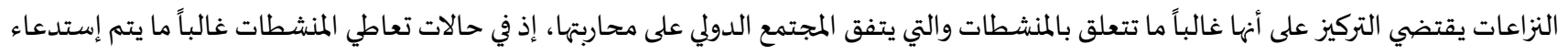

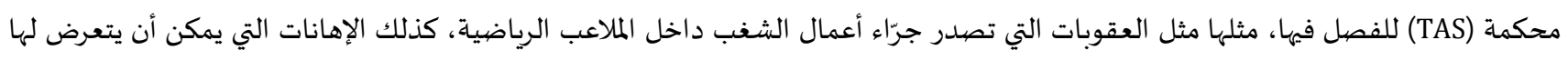

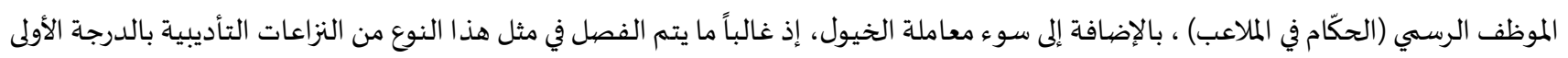

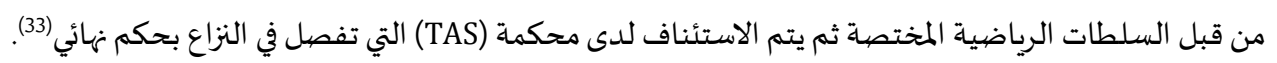

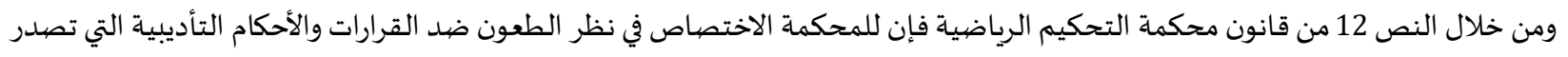

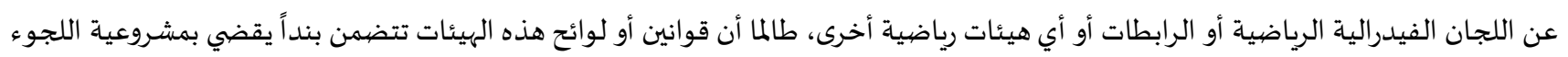

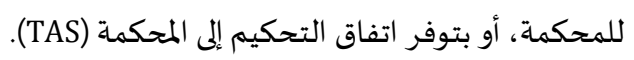

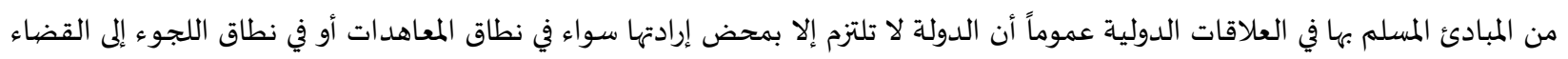

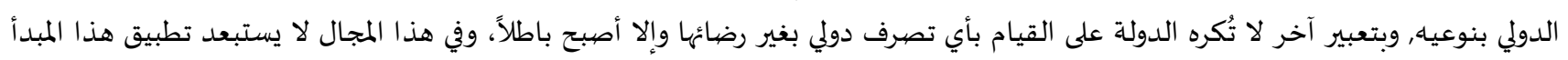

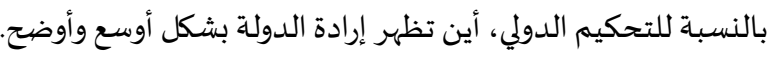

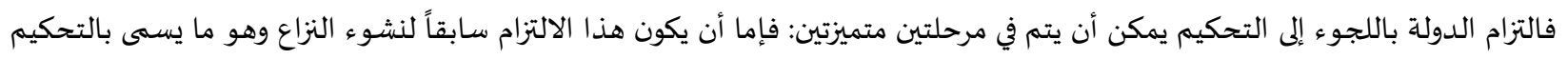

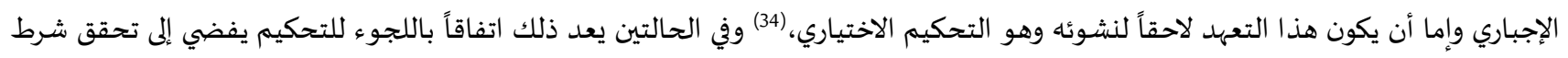

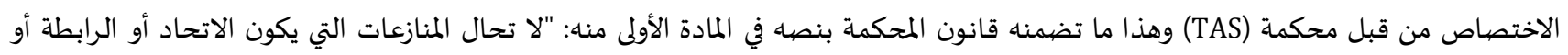

30 قواعد إجراءات التحكيم الرياضيكيك CAS ، حالة الهيئات المشاركة في تسوية النزاعات الرياضية، المادة رقم (2016).

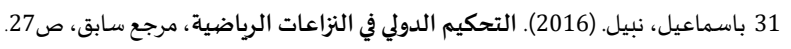

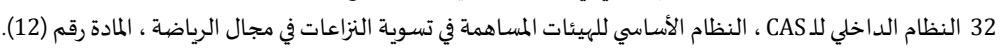

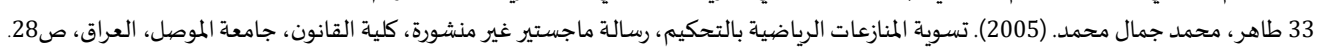

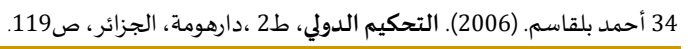


المنظمة الرياضية الأخرى طرفاً فها إلّا إلى التحكيم بالمعنى المقصود في هذه المدونة من حيث النظام الأساسي أو اللوائح الخاصة بالهيئات الرياضية المذكورة أو اتفاق خاص يقدم ذلك".(35) وقد احتوت محكمة (TAS)(بالإضافة إلى الطبيعة التجارية للنزاعات والتأديبية، نزاعات ذات طبيعة مؤقتتة، وهي النزاعات التي تنشأ أثناء الألعاب الأولمبية والتي لا يمكن إغفالها عن محكمة التحكيم الرياضية، إذ ينص الميثاق الأولمبي، في المادة 2/61 الفقرة الثانية التي تخول إلى محكمة (TAS)

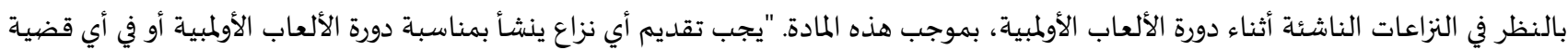

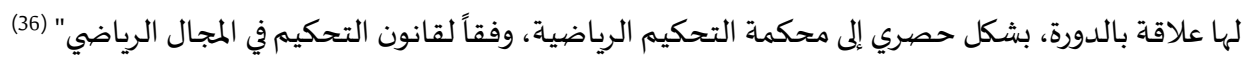

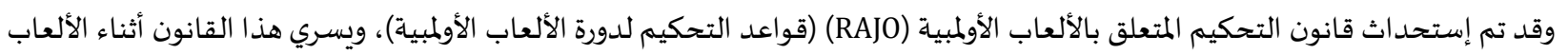

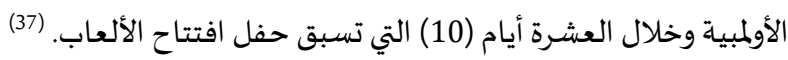

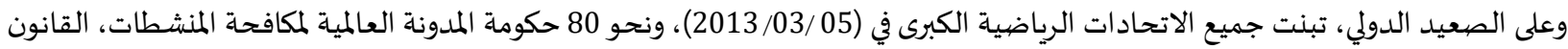
الذي ينص على أن للمحكمة (TAS) الاختصاص الحصري للنظر في الطعون ضد القرارات التي تصدر عن إختبارات الكشف للمنشطات في الأحداث الدولية أو على الرياضيين المحترفين على المستوى الدولي لـمة (38).

المطلب الثاني: القواعد القانونية المطبقة في محكمة التحكيم الرياضية الدولية لأجل حل الخلافات في المواضيع الرياضية عن طريق التحكيم والوساطة تم انشاء هيئتين دوليتين معتمدتين من اللجنة الأولمبية الدولية

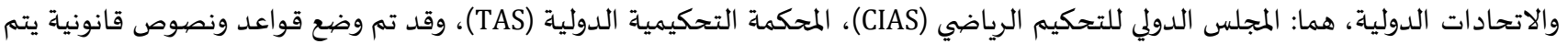

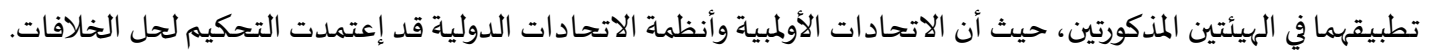

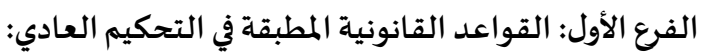

لكي تقوم الهيئتان الدوليتان في التحكيم الرياضي بعملهما على أتم وجه، وبهدف الرفع من فعالية وكفاءة عملية التحيكم في المنازعات الرياضية الدولية، تم الإعتماد على مجموعة من الأسس والقواعد الناظمة لعملية التحولئية التحكيم، سواء أكان التحكيم العادي أم التحكيم الاستئنافي. يتشكل المجلس الدولي للتحكيم الرياضي من عشرين عضوًا، خبراء وفقهاء في القانون، أربعة منهم يتم تعيينهم من قبل الاتحادات الرياضياة

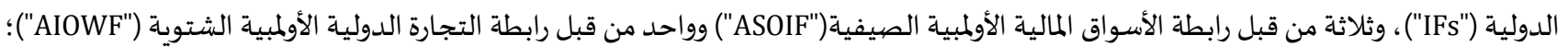
كما يتم تعيين أربعة أعضاء من قبل جمعية اللجان الأولمبية الوطنية ("ANOC")، وأربعة أعضاء يتم تعيينهم من قبل اللجنة الأولمبية الدولية ("اللجنة

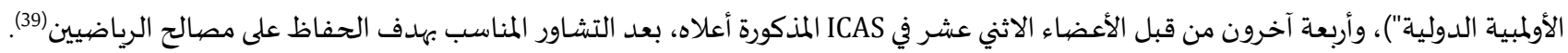
وهناك مجموعة من القواعد القانونية المطبقة في التحكيم العادي، يمكن إستعراضها في الآتي:

1. اللغة المعتمدة في المحكمة وإجراءات التقاضي مني

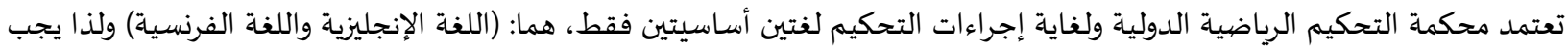

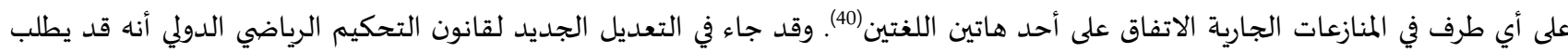

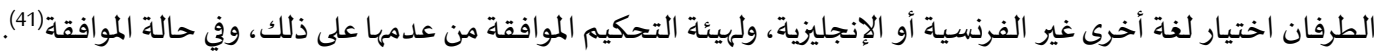

2.

في هذه القاعدة فإن محكمة التحكيم الرياضية الدولية تسمح لأطراف النزاع أن يتفقوا فيما بينهم حول طريقة تعيين الحكام المدرجة أسماؤهم

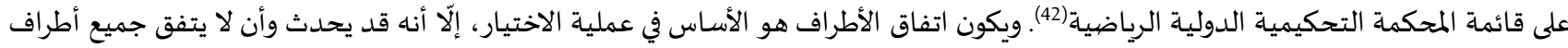

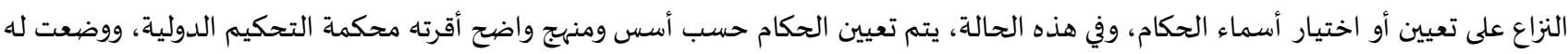

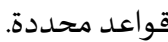

35 النظام الداخلي لنظام TAS ، النظام الأساسي للهيئات التي تسهم في تسوية النزاعات الرياضية، المادة رقم (1).

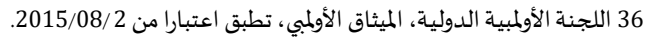
37 قواعد التحكيم للألعاب الأولمبية، المادة رقم (1).

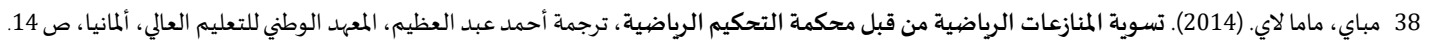

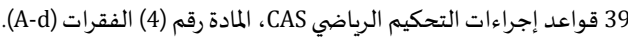

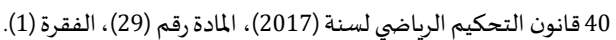

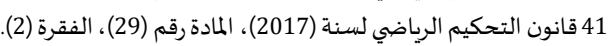
42 قانون التحكيم الرياضي لسنة (2017)، المادة رقم (40)، المادة (2017)، الفقرة (1). 


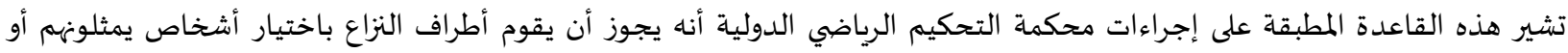

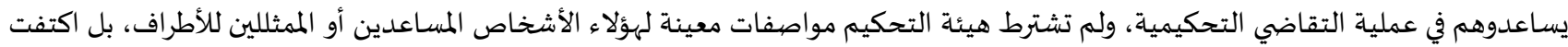

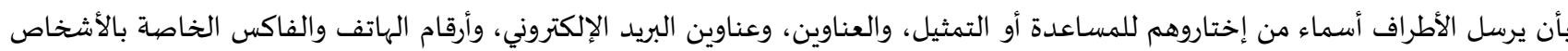

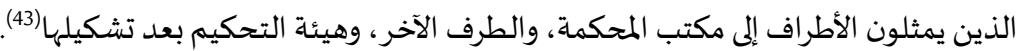

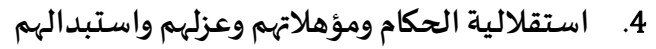

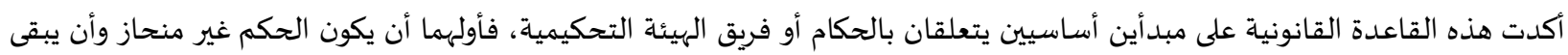

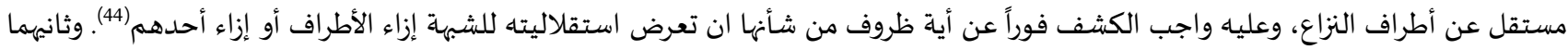

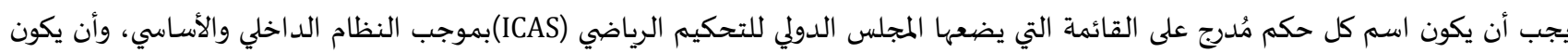
ضليعاً بلغة التحكيم وأن يكون جاهزاً للسير بالتحكيم إلى نهايته في أفضل المبل المواعيد (45). . الاجراءات بموجب هذه القواعد الإجرائية سريّة، يتعهد أطراف النزاع والحكام والمحكمة التحكيمية الدولية الرياضية بعدم الكشف أمام الترام

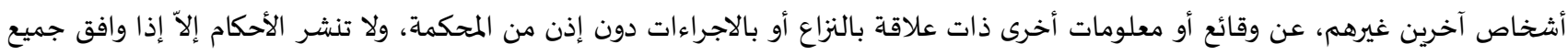

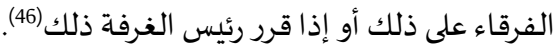
6.

يصدر الحكم التحكيهي بقرار الأغلبية، أو في حالة عدم وجود الأغلبية، من قبل الرئيس وحده، ويجب أن يكون الحُكم مكتوباً ومؤرخاً وموقعاً

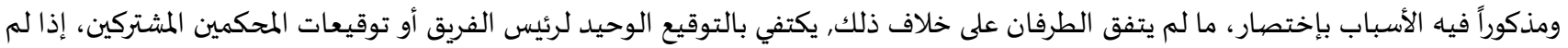

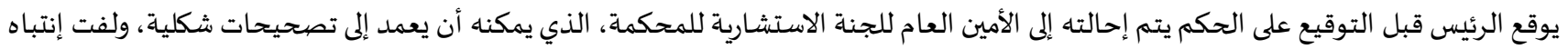

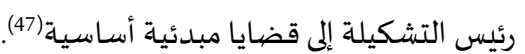

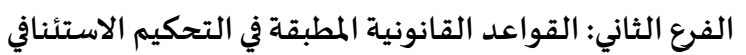

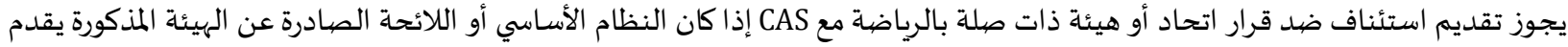

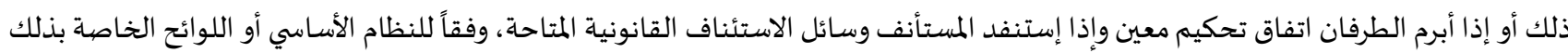

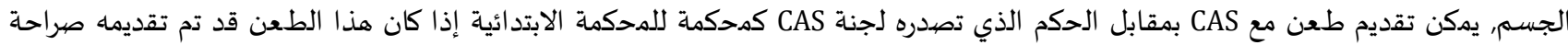

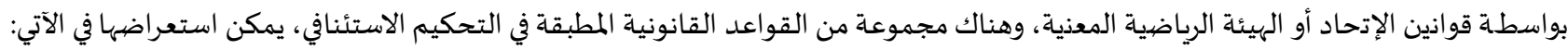
1. القانون واجب التطبيق

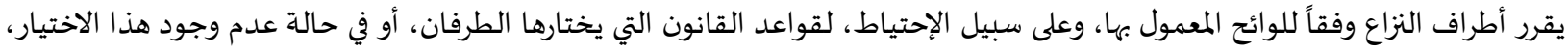

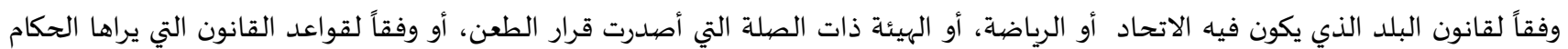

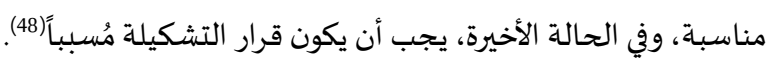

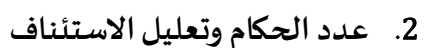

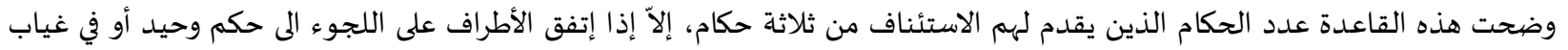

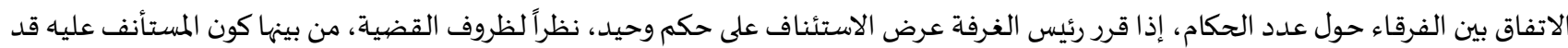

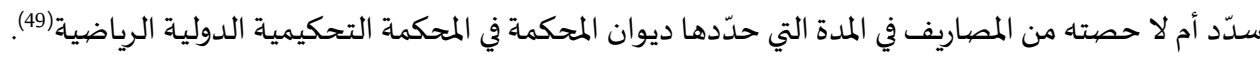

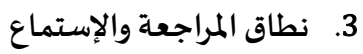

وفق هذه القاعدة القانونية يمتلك فريق المحكمين الصلاحية الكاملة لمراجعة الوقائع والقانون مع حق الدراسة المطلق. بإمكانها إما إصدار قرار

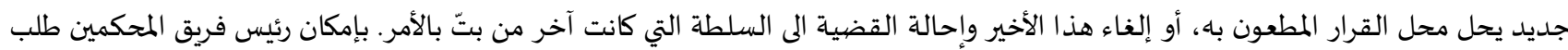

43 قانون التحكيم الرياضي لسنة (2017)، المادة رقم (30).

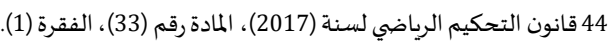

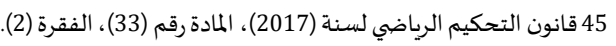

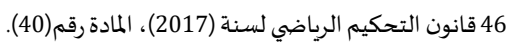

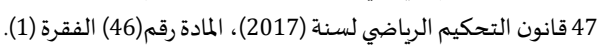
(2017) (2017)، المادة رقم(2017)، المادة (58).

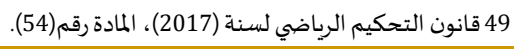


تزويده بملف الاتحاد، الجمعية أو الهيئة الرياضية التي أصدرت القرار المطعون به فور إحالة الملف، يحدد رئيس التشكيلة طرق الجلسة للإستماع الى الى الفرقاء والشهود والخبراء، وكذلك للمرافعات. 4.

تقرر هذه القاعدة أن الحكم الاستئنافي يصدر بالأكثرية أو في غياب الأكثرية، من قِبَّل الرئيس وحدهر ويكون الحكم مكتوباً مؤخراً وموقعاً ومسبباً

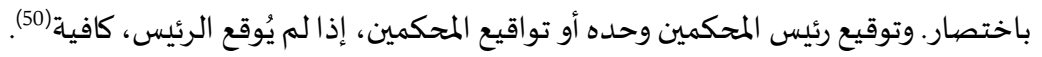

\section{المبحث الثاني: قرارات محكمة التحكيم الرياضية الدولية}

ينعقد اختصاص محكمة التحكيم الرياضية حين يتفق أطراف النزاع الرياضي على إحالة نزاعهم عليها، وذلك بناءً على شرط التحكيم الوارد في

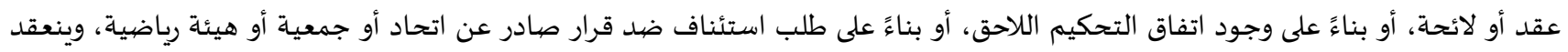
كذلك في حالة وجود اتفاق خاص يتضمن الطعن أمام محكمة التحكيم الرياضي، وإلى جانب الفصل وجود الفيل في النزاعات الرياضية التي ترفع اليها سواءً في

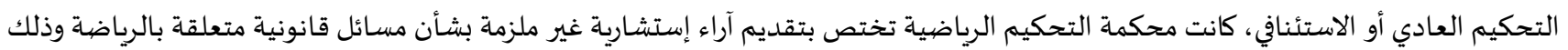

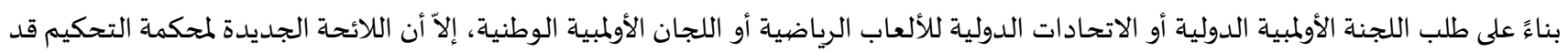
ألغت هذا الاختصاص لمحكمة التحكيم.

المطلب الأول: إجراءات التحكيم (التسوية - الاستئناف) أمام محكمة التحكيم الرياضية الدولية

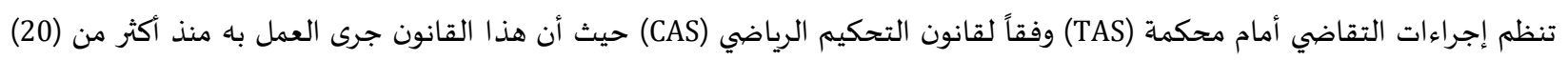

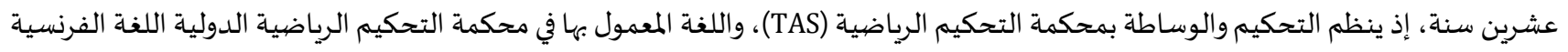
والإنجليزية، ويجوز تمثيل الأطراف أو بمساعدة من قبل أشخاص من اختيارهم، وتتم الإخطارات والإتصالات إلى قلى قلم المحكمة (الأمانة العامة

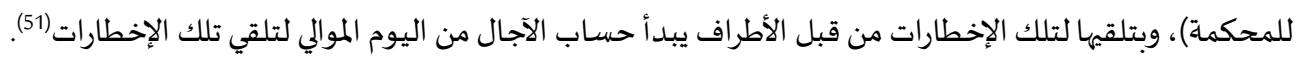

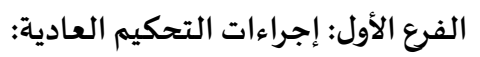
تسري هذه الاجراءات أمام غرفة التحكيم العادية لمحكمة التحكيم (TAS) وفقاً لنصيوص المواداد التهادئ من ( 38 إلى 46)(52) من قانون التحكيم الرياضي

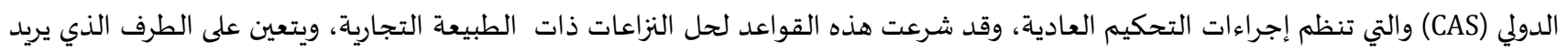

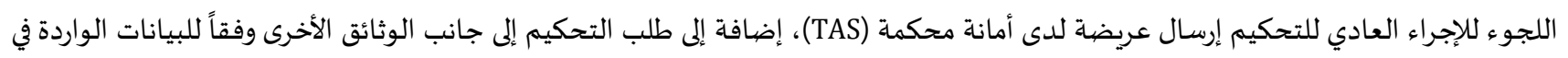

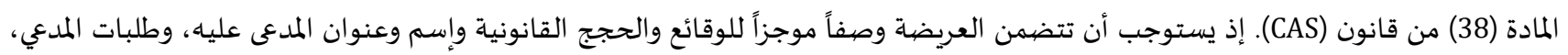
ونسخة من اتفاق التحكيم ومعلومات عن اختيار المحكمين وعددهنم.

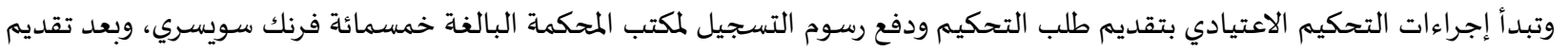

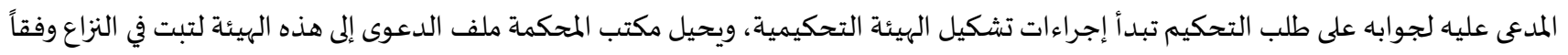

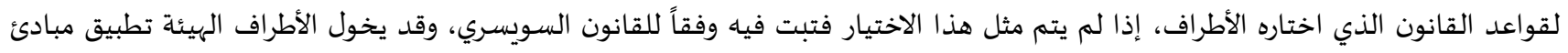

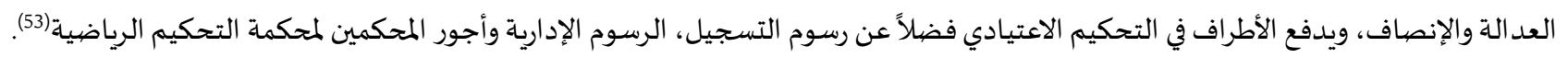

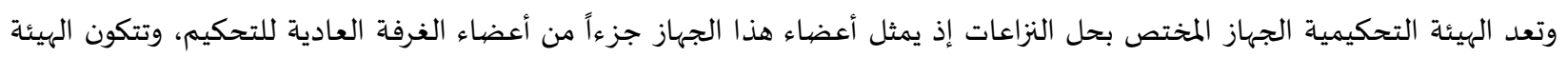

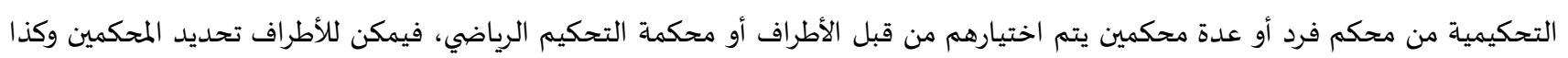

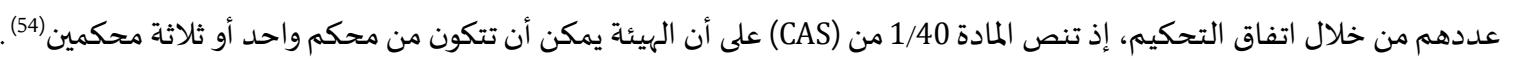

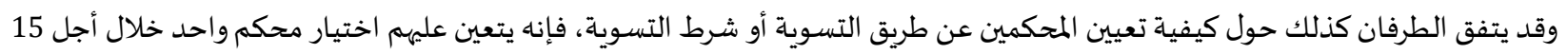

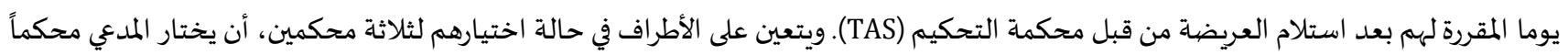

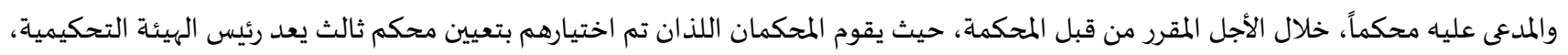

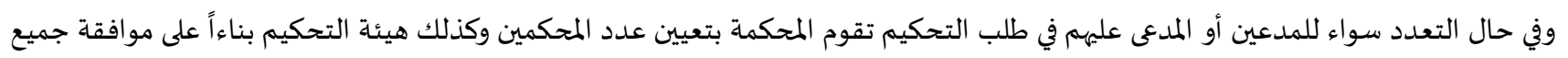
الأطراف, وإذا كان هناك ثلاثة أطراف أو أكثر لهم مصالح متباينة يتم تعيين المحكمان وفقاً لاتفاق الأطراف (55.

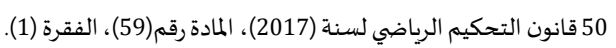

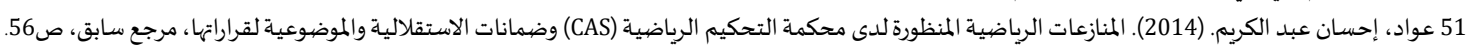

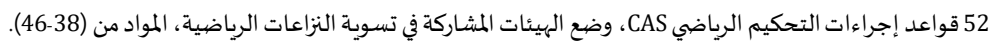

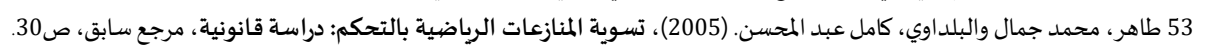

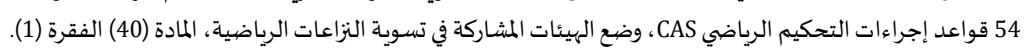

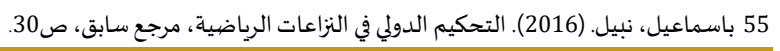


وتنص المادة (44) من قانون التحكيم الرياضي(56)على كيفية سير الاجراءات أمام الغرفة العادية، حيث تتم هذه الاجراءات إما كتابة أو شفاهة،

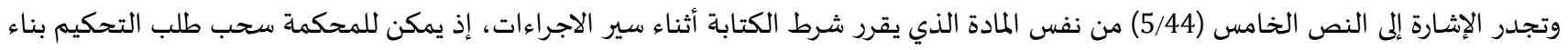
على تخلف أحد الأطراف عن شرط كتابة مذكراته، ما هو معمول باه في العديد من القوانين المنظمة للتحكيم.

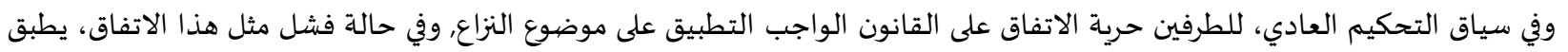

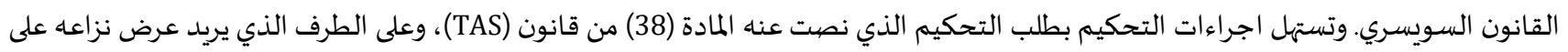

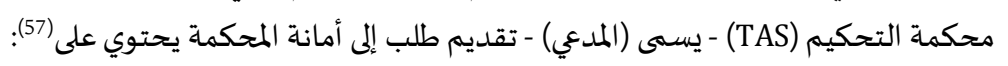
الاسم والعنوان الكامل للمدعى عليه.

بيان موجز بالوقائع والحجج القانونياة، بما في ذلك بيان للقضية بتقديمها إلى TAS للتقرير. الطلبات.

نسخة من اتفاق التحكيم أو من أي وثيقة تنص على التحكيم لدى محكمة TAS. أي معلومات عن اختيار وعدد المحكم أو المحكمين.

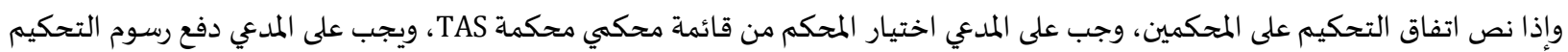
المنصوص عليها في المادة (1/64) من قانون (CAS). الفرع الثاني: إجراءات التحكيم بالاستئناف: نظمت محكمة (TAS) إجراءات التحكيم بالاستئناف في المواد من (47 إلى 59) من قانون (CAS) تسمح هذه الاجراءات للمحكمة بالنظر في

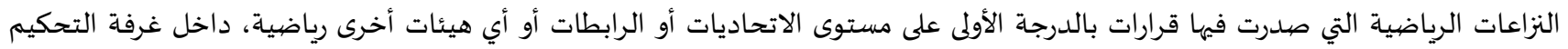

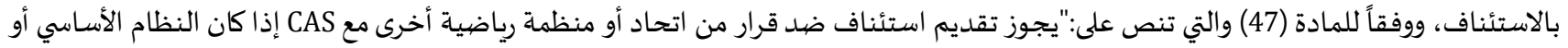

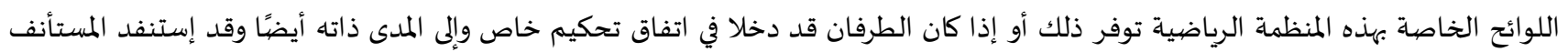

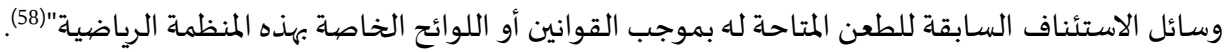

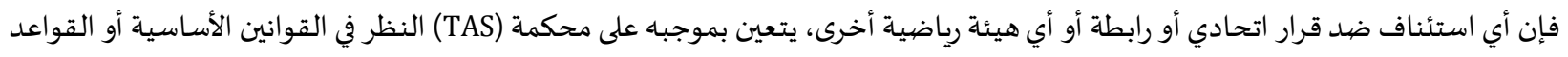

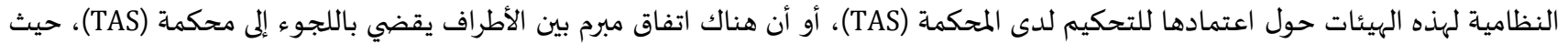

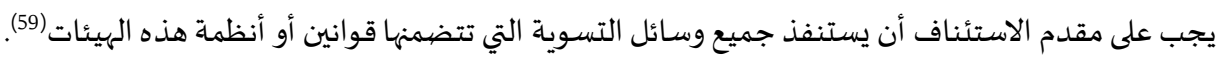

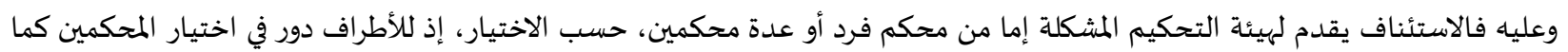

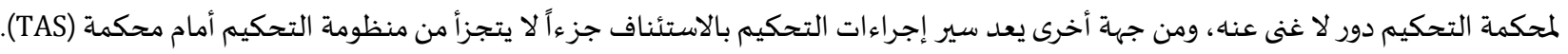

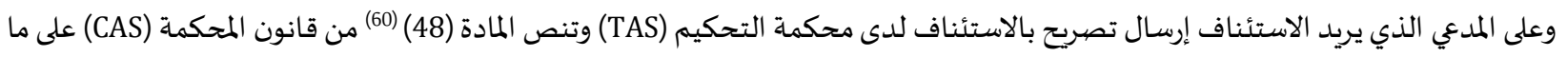

يجب أن يتضمنه التصريح بالاستئناف (بيان الاستئناف)، إذ يجب أن يتضيمن التصيريت المعلومات المبناف التالية: الإسبم والعنوان الكامل للمدعى علياء أو المدعى عليهم.

نسخة من القرار المطعون فيه. طلبات المستأنف.

تعيين المحكم الذي يختاره مقدم الطلب على قائمة المحكمين (TAS)، ما لم يطلب تعيين محكم واحد. إذا اقتضى الأمر، عريضة مسببة لمفعول الإيقاف.

نسخة من الأحكام القانونية أو التنظيمية أو اتفاق محدد ينص على جوازية الاستئناف أمام (CAS).

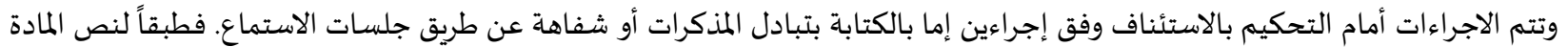

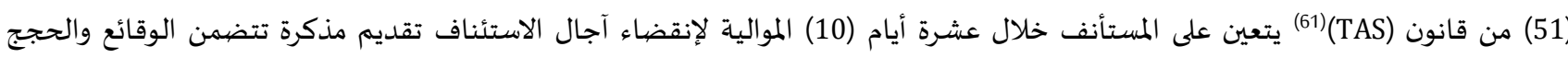

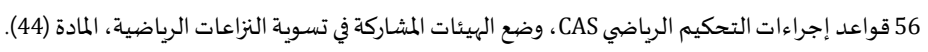

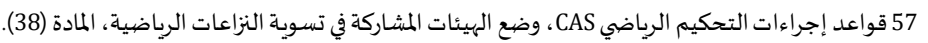

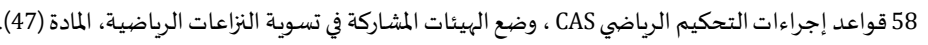

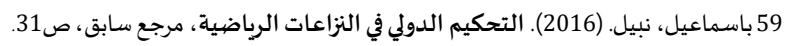

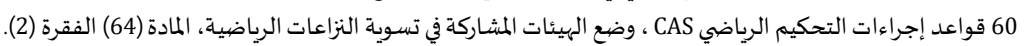

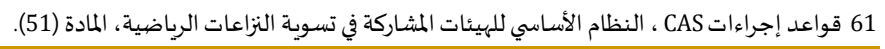


القانونية ،مصحوباً بجميع المستندات والأدلة التي يرغب في الإعتماد علهها ،حيث وبنفس الآجال يتوجب عليه إعلام أمانة المحكمة كتابة وبنفس الآجال

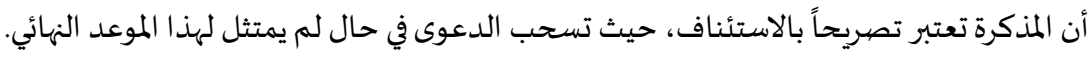

المطلب الثاني: حجية قرارات محكمة التحكيم الرياضية الدولية

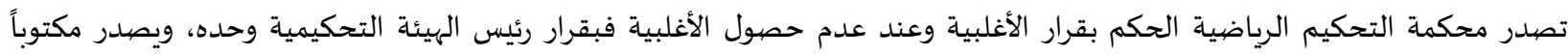

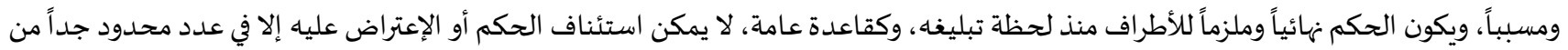

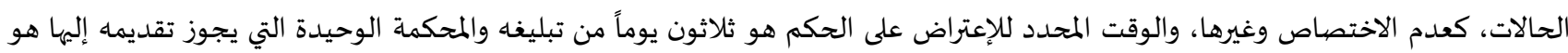
المحكمة الفدرالية السويسرية (62). الفرع الأول: حجية القرارات

وفقاً للنظام الاساسي للفيفا فإن أعضاء الاتحاد الدولي لكرة القدم يتعهدون بالاعتراف بمحكمة التحكيم الرياضية كجهة قضائية مستقلة

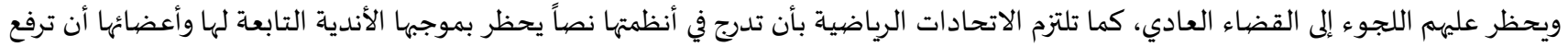

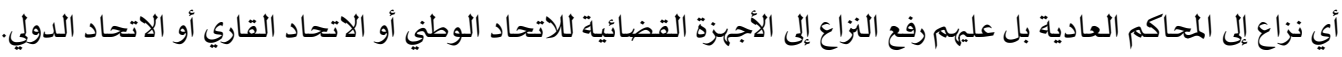

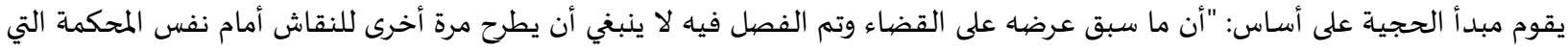

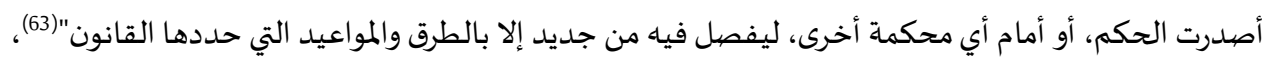

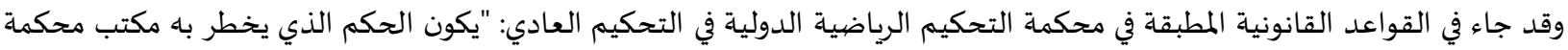

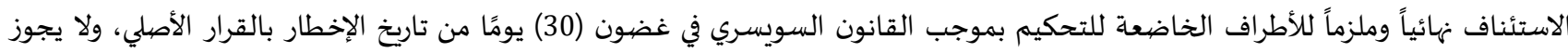
الطعن فيه عن طريق إجراء جانبي"(64). كما جاء في القواعد القانونية المطبقة في محكمة التحكيم الرياضية الدولية في التحكيم الاستئنافي: "يكون قرار الحكم نهائياً وملزماً للأطراف وغير

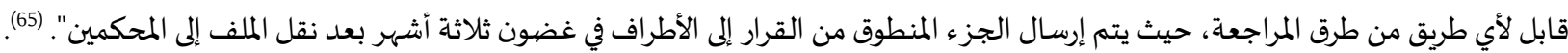

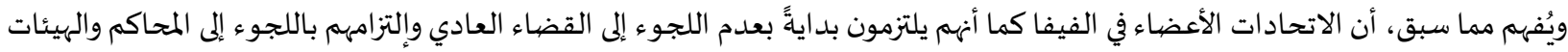

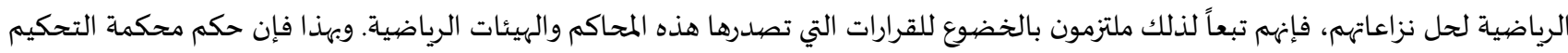
الرياضية الدولية لديها حجية مطلقة وتنفذ على أطراف النزاع من الاتحادات واللاعبي ووكلاههم، وبما أن حكم التحكيم الصادر من من محكمة مكاعة التحكيم

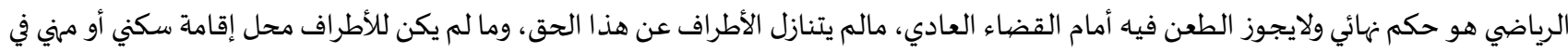
سيويسرا عندها يجوز الطعن أمام المحكمة الاتحادية السويسرية. ويلاحظ أن قرارات محكمة التحكيم الرياضية هي واجبة التنفيذ وفقاً لاتفاقية نيويورك بشأن الإعتراف وتنفيذ أحكام محاكم التنفيذ الأجنبية لسنة 1958 وتخضع قرام المارات محكمة التحكيم الرياضي وفقاً لهذه الاتفاقية إلى القواعد الداخلية في الدولة المطلوب تنفيذها فياء.

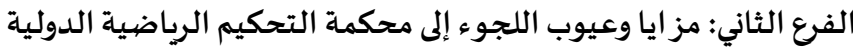

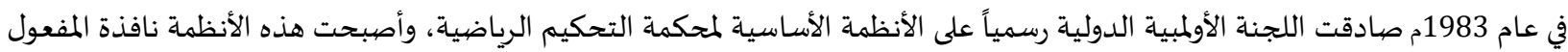
في 1984/6/30، وسميت بمحكمة التحكيم الرياضية ويكون مقرها في لوزان في سويسرا، "وتحتص هذه المحكمة بتسوية المنازعات القانونية - الرياضية

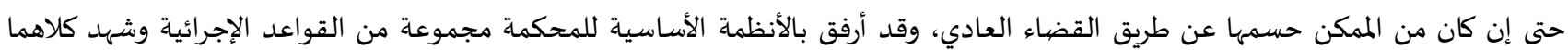

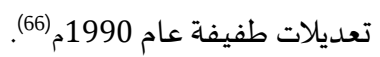

ومن مز ايا اللجوء إلى محكمة التحكيم الرياضية التهية الدولية: 1. تكون إجراءات التحكيم مناسبة لحسم المنازعات الرياضية الدولية: غالباً تختلف جنسية المتنازعين في قضية ما خصوصياً في عصر الاحتراف

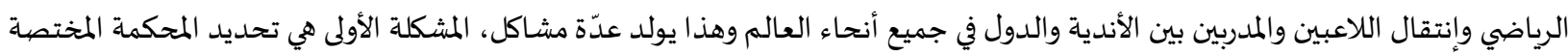
بالنظر بالمنازعة، ثم تحديد القانون الواجب التطبيق على المنازعاة، أضف لذلك اللغة والترجمة عند رفع الدعوى في بلد أجنبي وما يتعلق بإجراءات الدعوى لذلك البلد (67).

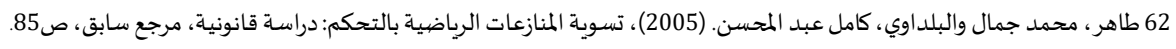

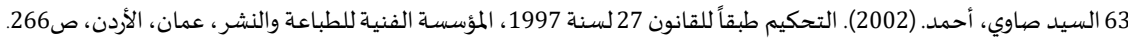

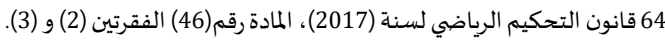

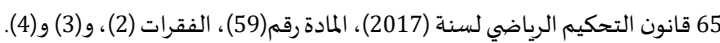

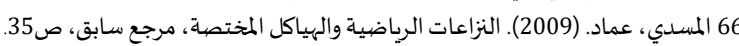

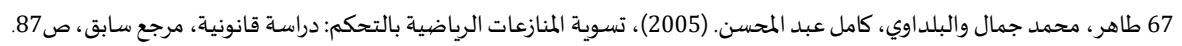


2. تفاصيل المنازعات الرياضية بحاجة لمعرفة عميقة بالرياضة لا يمتلكها القاضي العادي: إذ أن المحكمين في هذه المحكمة شخصيات ذو

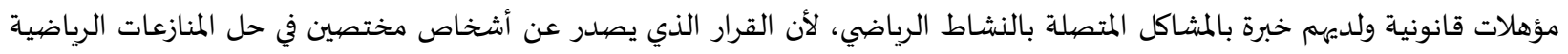

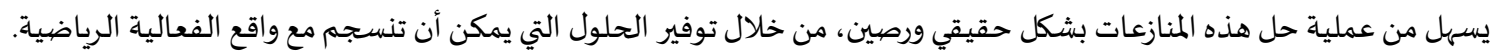

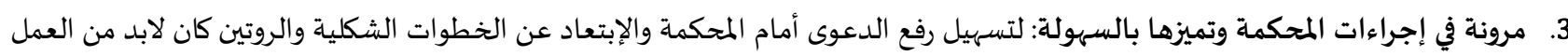

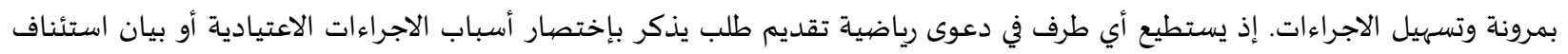

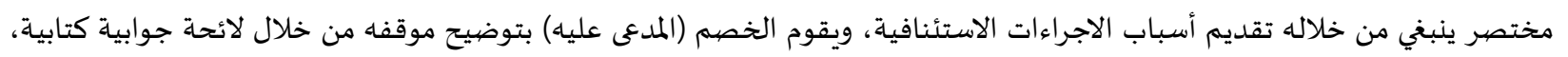

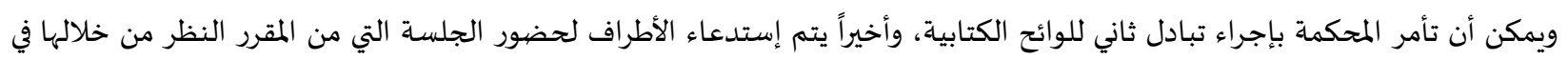

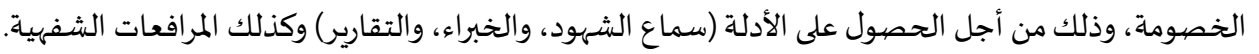

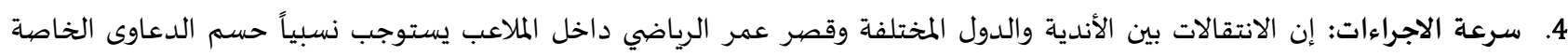

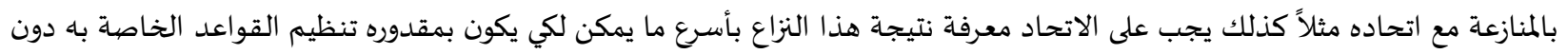

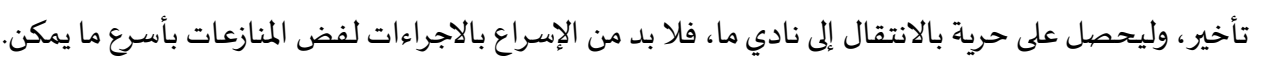

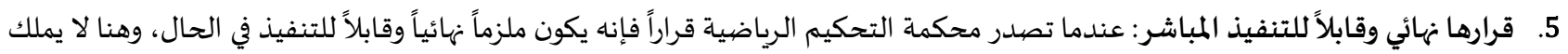

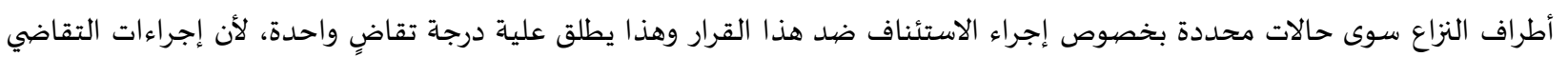

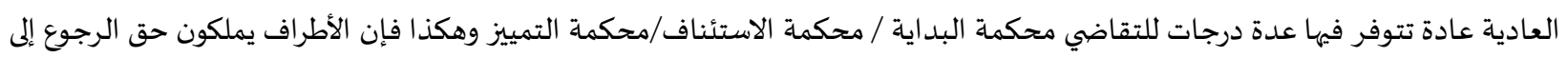

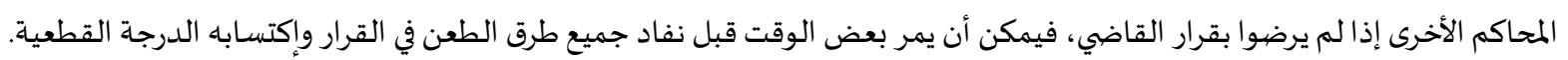

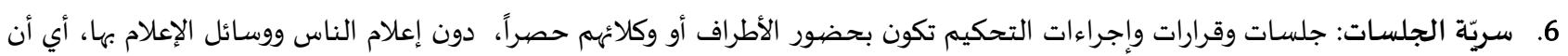

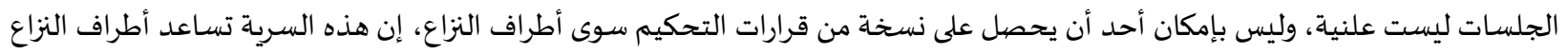

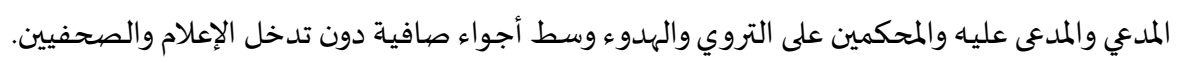

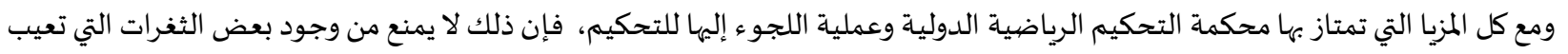
هذا النظام ومنها(68): 1. التخلي المتوقع عن طرق الطعن التي من الممكن إتخاذها ضد قرارات المحاكم العادياة، كما يؤخذ على سرعة إجراءاتها أنها قد تكون مضللة أو مربكة في بعض الأحيان. 2. منح الأطراف حرية اختيار القانون الواجب التطبيق على التحكيم قد يؤدي ذلك أن يتم هذا الاختيار بسوء نيّة، أي أن يتعسف الأطراف في

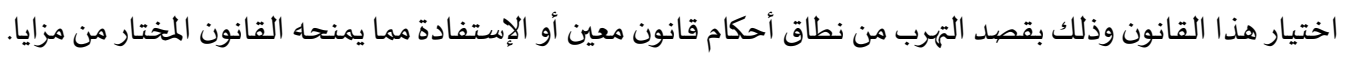

جاء هذا البحث بهدف التعرف على التحكيم في المنازعات الرياضية وفق محكمة التحكيم الرياضية الدولية. وقد خلص البحث إلى مجموعة من النتائج والتوصيات كما يلي: يعد التحكيم الرياضي وسيلة فعالة لتسوية المنازعات المتعلقة بالجانب الرياضي عن طريق محكم أو مجموعة محكمين تتفق أطراف النزاع على الميلى القبول بهم وبالإجراء ات المتبعة من قبل المحكمة وقبول وتنفيذ القرارات الصيادرة عنهم. تم إنشاء المجلس الدولي للتحكيم الرياضي سنة 1994، كجهاز يضمن استقلال محكمة التحكيم الرياضية الدولية عن اللجنة الأولمبية المنشأة له من خلال وظيفة التسيير المالي والإداري للمحكمة، وكذلك عن طريق إنشاء وتعديل القواعد التنظيمية الخاصية بسير المحكمة وكذلك سير إجراءات التحكيم أمامها.

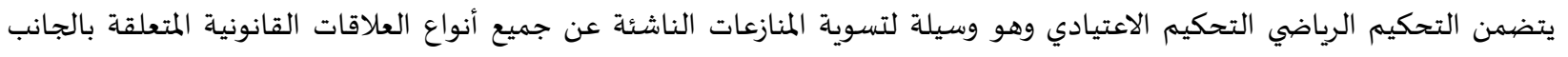
الرياضي، والتحكيم الاستئنافي لتسيوية المنازعات الناشئة عن القرارات الصادرة بدرجة أخيرة عن محاكم منظمة مختصية أو أو محاكم مماثلة تعمل

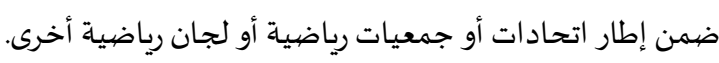

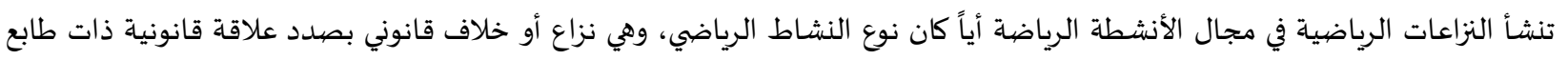
رياضي من أي نوع كانت.

68 عواد، إحسان عبد الكريم. (2014). المنازعات الرياضية المنظورة لدى محكمة التحكيم الرياضية (CAS) وضمانات الاستقلالية والموضوعية لقراراتها، مرجع سابق، ص62. 
تقسّم المنازعات المرفوعة إلى محكمة التحكيم الرياضية الدولية، من حيث طبيعتها إلى نزاعات ذات طبيعة مالية ونزاعات ذات طبيعة انضباطية

يختص التحكيم الاستئنافي بالنظر في النزاعات الرياضية التي صدر في صددها قرار تأديبي من اتحاد رياضي أو من منظمة رياضية أو أية جهة تابعة لها، إذا كان النظام الداخلي أو اللائحة الخاصة بتلك الجهات التهات تشير إلى جواز استئناف تلك الأحكام أمام محكمة التحكيم الرياضية. ينعقد اختصاص محكمة التحكيم الرياضياة حين يتفق أطراف النزاع الرياضي على إحالة نزاعهه عليها، بناءاً على شرط التحكيم الوارد في عقد أو

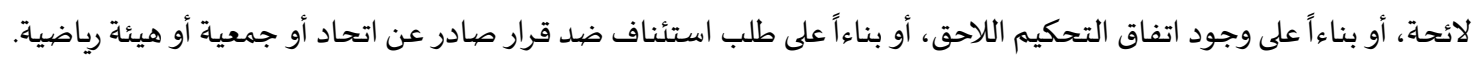

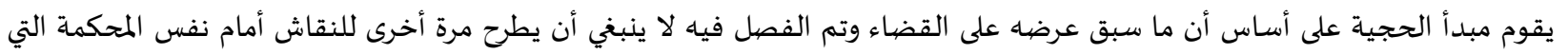

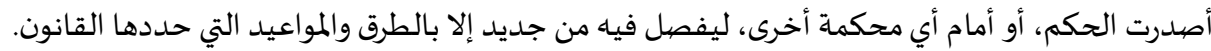
حجية الحكم الصادر عن محكمة التحكيم الرياضية الدولية حجية مطلقة وتنفذ على أطراف النزاع من الاتحادات واللاعبين ووكلاههم، وهو

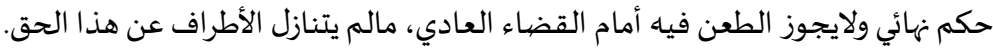
من ميزات اللجوء إلى محكمة التحكيم الرياضية الدولية أن إجراءتها سريعة ومناسبة لحسم المنازعات الرياضية الدولية، بالإضافة إلى المعرفة

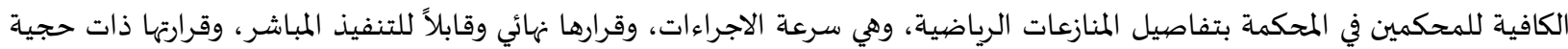
مطلقة وملزمة. التوصيات:

إصدار لائحة تنفيذية باختصاصـات وضوابط وإجراءات التقاضي لمحكمة التحكيم الرياضي الدولية، تكون معتمدة من مختلف اللجان والهيئات الرياضية المحلية، والدولية على حد سواء. تخفيض تكاليف اللجوء إلى محكمة التحكيم الرياضي الدولية، وإنشاء فروع لها في مختلف مناطق العالم بهدف تسهيل الوصول إلها، وحتى لا يحدث تردد من المتنازعين للجوء إلهها. السعي نحو إعتماد اللغة العربية كلغة أساسية معتمدة ثالثة جنباً إلى جنب مع اللغة الفرنسية والإنجليزية في محكمة التحكيم الرياضي الدولية. العمل على إنشاء محاكم تحكيم رياضي وطنية على غرار محكمة التحكيم الدولية، وترتبط معها في قراراتها.

1. أحمد بلقاسم (2006). التحكيم الدولي. ط2 ـ دار هومة. الجزائر.

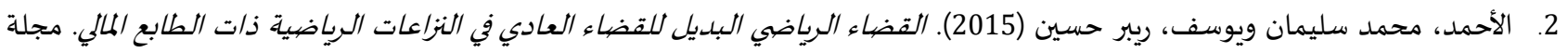

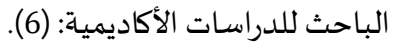
3. باسماعيل، نبيل (2016). التحكيم الدولي في النزاعات الرياضية. رسالة ماجستير غير منشورة. كلية الحقوق والعلوم السياسية. جامعة قاصديدي مرباح. ورقلة. الجزائر.

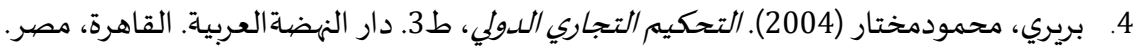

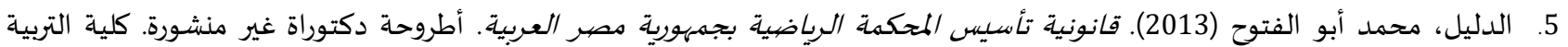
الرياضياة للبنين. جامعة بنها. 6. السرحان، بكر ودرادكة، لافي (2009). آلية تنفين أحكام التحكيم في الأردن: دراسة تقييميّة في ظل قانون التحكيم رقم 31 لسنة 2001م. مجلة المنارة: (2) 7. سفلو عبد الرزاق (2011). الطبيعة القانونية لعقد الاحتراف الرياضي. ط 3. مكتبة صادر ناشرون. بيروت. 8. السيد صاوي، أحمد (2002). التحكيمر طبقاً للقانون 27 لسنة 1997. المؤسسة الفنية للطباعة والنشر. عمان. الأرسان.

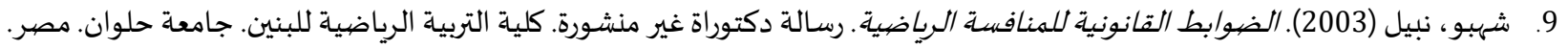

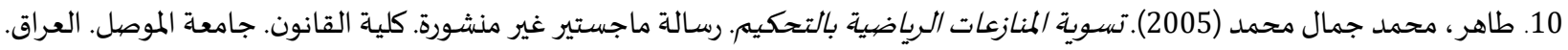

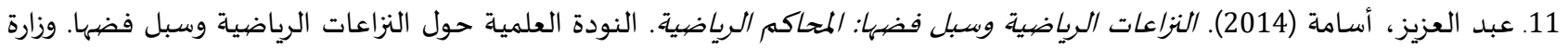
العدل المصرية. مصر. 12. عبد النعيم، محمد أحمد (2007). تسوية النزاعات الناشئة عن حل مجالس إدارة الأندية الرياضية بين دور القضياء الإداري وإمكانية التسيوية

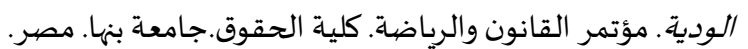


13. عواد، إحسان عبد الكريم (2014). المنازعات الرياضية المنظورة للىى محكمة التحكيم الرياضية (CAS) وضمانات الاستقلالية والموضيوعية

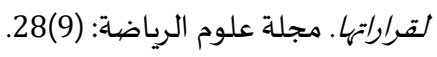

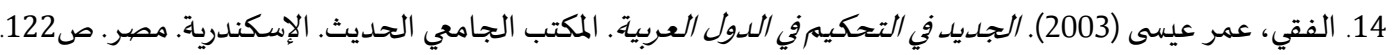
15. قانون اتحادي في شأن مركز الإمارات للتحكيم الرياضي، رقم 16 لسنة 2016.

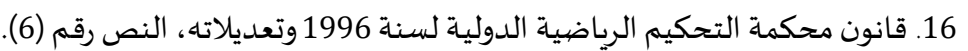
17. قواعد إجراءات التحكيم الرياضي CAS، المادة (3).

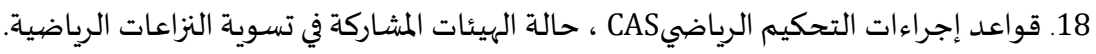
19. القواعد الإجرائية لمركز التحكيم الرياضي السعودي لسنة 2014. 20. قواعد التحكيم الرياضي التونسي لسنة 2012. 21. قواعد تنظيم الأنشطة البدنية والرياضية وتنظيمها رقم (13) لسنة 2013.

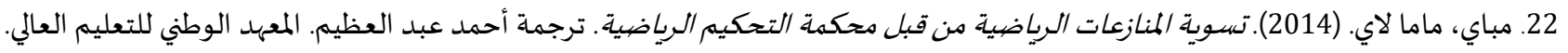

23. المسـدي، عماد (2009). النزاعات الرياضية والهياكل المختصية. مجلة بحوث ودراسات قانونية: جمعية الحقوقيين بصفاقس. (4)3.

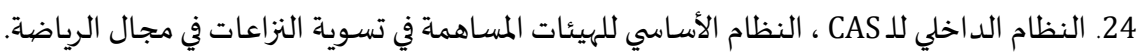




$$
\text { المجلة الدولية للدراسات القانونية والفقهية المقارنة }
$$

International Journal of Legal and Comparative Jurisprudence Studies (LCJS)

www.refaad.com

Journal Homepage: https://www.refaad.com/views/LCJS/Home.aspx

ISSN: 2708-6607(Online) 2708-6593(Print)

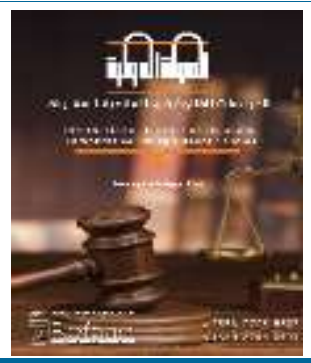

\title{
Arbitration in sport disputes according to the rules of the international court of arbitration for sport
}

\author{
Ayed Ahmed Al Kharabsheh \\ PhD student, The World Islamic Sciences \& Education University, Jordan \\ sahelaliatoom@gmail.com
}

\begin{abstract}
Received: 31/12/2020 Revised: 17/2/2021 Accepted: 6/3/2021 DOI: https://doi.org/10.31559/LCJS2021.2.1.2
Abstract: This study aimed to identify arbitration in sports disputes according to the rules of the International Sports Arbitration Court, by learning about the nature of the jurisdiction of this court and the nature of the disputes it is considering, as well as the applicable legal rules, and identifying the procedures for arbitration and settlement in sports disputes in the International Sports Arbitration Court, The problem of the study emerges from the peculiarity of the Court of Arbitration for Sport in that it considers all disputes that arise in the field of sports and this contravenes the rules and principles of international arbitration, as well as the difference in the rules applied in resolving these disputes in the field of sports, and to achieve the objectives of the study was relied on the descriptive and analytical approach, and that from During the review of the various concepts related to the subject of the study, and identification of the form, composition, work procedures and the functioning of the International Sports Arbitration Court.

The study found a set of results, the most important of which are: that sports disputes arise in the field of sports activities, whatever the type of sporting activity, and it is a legal dispute or dispute regarding a legal relationship of a sporting nature of any kind, and that the Sports Arbitration Court is an independent institution that provides its services from In order to facilitate the resolution of sports-related disputes through arbitration or mediation, one of the advantages of resorting to this court is that its procedures are quick and appropriate to resolve international sports disputes, in addition to adequate knowledge of the arbitrators in the court of the details of sports disputes, and its decisions are absolutely authoritative and binding, and the study recommended a set of recommendations from The most important of them are: Reducing the costs of resorting to the International Court of Arbitration for Sport, establishing branches for it in various regions of the world in order to facilitate access to it, and so that disputants do not hesitate to resort to it, as well as striving to adopt Arabic as a third approved primary language along with French and English in International Court of Arbitration for Sport.
\end{abstract}

Keywords: International Sports Arbitration; Sports Disputes; International Sports Arbitration Court.

\section{References:}

1. 'bd Al'zyz, Asamh (2014). Alnza'at Alryadyh Wsbl Fdha: Almhakm Alryadyh. Alnwdh Al'Imyh Hwl Alnza'at Alryadyh Wsbl Fdha. Wzart Al'dl Almsryh. Msr.

2. 'bd Aln'ym, Mhmd Ahmd (2007). Tswyh Alnza'at Alnash'h 'n Hl Mjals Edart Alandyh Alryadyh Byn Dwr Alqda' Aledary Wemkanyh Altswyh Alwdyh. M'tmr Alqanwn Walryadh. Klyt Alhqwq. Jam't Bnha. Msr.

3. 'wad, Ehsan 'bd Alkrym (2014). Almnaz'at Alryadyh Almnzwrh Lda Mhkmh Althkym Alryadyh (Cas) Wdmanat Alastqlalyh Walmwdw'yh Lqraratha. Mjlt 'lwm Alryadh: (9)28.

4. Ahmd Blqasm (2006). Althkym Aldwly. T 2. Dar Hwmh. Aljza'r.

5. Alahmd, Mhmd Slyman Wywsf, Rybr Hsyn (2015). Alqda' Alryady Albdyl Llqda' Al'ady Fy Alnza'at Alryadyh Dat Altab' Almaly. Mjlt Albahth Lldrasat Alakadymyh: (6). 
6. Basma'yl, Nbyl (2016). Althkym Aldwly Fy Alnza'at Alryadyh. Rsalt Majstyr Ghyr Mnshwrh. Klyt Alhqwq Wal'lwm Alsyasyh. Jam't Qasdy Mrbah. Wrqlh. Aljza'r.

7. Bryry, Mhmwdmkhtar (2004). Althkym Altjary Aldwly, T3. Dar Alnhdhal'rbyh. Alqahrh, Msr.

8. Aldlyl, Mhmd Abw Alftwh (2013). Qanwnyh Tasys Almhkmh Alryadyh Bjmhwryt Msr Al'rbyh. Atrwht Dktwrah Ghyr Mnshwrh. Klyt Altrbyh Alryadyh Llbnyn. Jam't Bnha.

9. Alfqy, 'mr 'ysa (2003). Aljdyd Fy Althkym Fy Aldwl Al'rbyh. Almktb Aljam'y Alhdyth. Aleskndryh. Msr. S122.

10. Mbay, Mama Lay. (2014). Tswyh Almnaz'at Alryadyh Mn Qbl Mhkmt Althkym Alryadyh. Trjmt Ahmd 'bd Al'zym. Alm'ehd Alwtny Llt'lym Al'aly. Almanya.

11. Almsdy, 'mad (2009). Alnza'at Alryadyh Walhyakl Almkhtsh. Mjlt Bhwth Wdrasat Qanwnyh: Jm'yt Alhqwqyyn Bsfaqs. (4) 3.

12. Alnzam Aldakhly Ll CAS, Alnzam Alasasy Llhy'at Almsahmh Fy Tswyt Alnza'at Fy Mjal Alryadh.

13. Qanwn Athady Fy Shan Mrkz Alemarat Llthkym Alryady, Rqm 16 Lsnh 2016.

14. Qanwn Mhkmt Althkym Alryadyh Aldwlyh Lsnh 1996 Wt'dylath, Alns Rqm (6).

15. Qwa'd Ejra'at Althkym Alryady CAS, Almadh (3).

16. Qwa'd Ejra'at Althkym Alryady CAS, Halh Alhy'at Almsharkh Fy Tswyh Alnza'at Alryadyh.

17. Alqwa'd Alejra'yh Lmrkz Althkym Alryady Als'wdy Lsnh 2014.

18. Qwa'd Althkym Alryady Altwnsy Lsnh 2012.

19. Qwa'd Tnzym Alanshth Albdnyh Walryadyh Wtnzymha Rqm (13) Lsnh 2013.

20. Sflw (2011). Altby'h Alqanwnyh L'qd Alahtraf Alryady. T 3. Mktbt Sadr Nashrwn. Byrwt.

21. Shhbw, Nbyl (2003). Aldwabt Alqanwnyh Llmnafsh Alryadyh. Rsalt Dktwrah Ghyr Mnshwrh. Klyt Altrbyh Alryadyh Llbnyn. Jam't Hlwan. Msr.

22. Alsrhan, Bkr Wdradkh, Lafy (2009). Alyt Tnfyd Ahkam Althkym Fy Alardn: Drash Tqyymyh Fy Zl Qanwn Althkym Rqm 31 Lsnh 2001m. Mjlt Almnarh: (2)15.

23. Alsyd Sawy, Ahmd (2002). Althkym Tbqaan Llqanwn 27 Lsnh 1997. Alm'ssh Alfnyh Lltba'h Walnshr. 'man. Alardn.

24. Tahr, Mhmd Jmal Mhmd (2005). Tswyt Almnaz'at Alryadyh Balthkym. Rsalt Majstyr Ghyr Mnshwrh. Klyt Alqanwn. Jam't Almwsl. Al'raq. 